\title{
RNA-Binding Protein Hermes/RBPMS Inversely Affects Synapse Density and Axon Arbor Formation in Retinal Ganglion Cells In Vivo
}

\author{
Hanna Hörnberg, Francis Wollerton-van Horck, Daniel Maurus, Maarten Zwart, Hanno Svoboda, William A. Harris, \\ and Christine E. Holt \\ Department of Physiology, Development and Neuroscience, University of Cambridge, Cambridge CB2 3DY, United Kingdom
}

\begin{abstract}
The RNA-binding protein Hermes [RNA-binding protein with multiple splicing (RBPMS)] is expressed exclusively in retinal ganglion cells (RGCs) in the CNS, but its function in these cells is not known. Here we show that Hermes protein translocates in granules from RGC bodies down the growing axons. Hermes loss of function in both Xenopus laevis and zebrafish embryos leads to a significant reduction in retinal axon arbor complexity in the optic tectum, and expression of a dominant acting mutant Hermes protein, defective in RNA-granule localization, causes similar defects in arborization. Time-lapse analysis of branch dynamics reveals that the decrease in arbor complexity is caused by a reduction in new branches rather than a decrease in branch stability. Surprisingly, Hermes depletion also leads to enhanced early visual behavior and an increase in the density of presynaptic puncta, suggesting that reduced arborization is accompanied by increased synaptogenesis to maintain synapse number.
\end{abstract}

\section{Introduction}

Correct axon guidance and target recognition during development is crucial for establishing the accurate patterning of neuronal circuits in the brain. To navigate correctly to their target areas, axons must respond rapidly to guidance cues in their environment. Accumulating evidence suggests that the response to many of these guidance cues involves local protein synthesis in the axon and growth cone itself (Campbell and Holt, 2001; Hengst and Jaffrey, 2007; Lin and Holt, 2007; Jung et al., 2012). Genomewide analyses have shown that hundreds of different mRNAs reside in growing axons and growth cones (Zivraj et al., 2010, Gumy et al., 2011). Moreover, the mRNA repertoire differs in navigating versus target-arrived axons (Zivraj et al., 2010), suggesting that a temporal and spatial regulation of mRNA is important for correct circuit formation.

RNA-binding proteins (RBPs) are central players in mRNA processing, regulating the trafficking, cellular location and translation of their target mRNAs (Lunde et al., 2007). Many neuronal RBPs are expressed in a region-specific manner (McKee et al., 2005) and some RBPs, such as Vg1RBP (ZBP1), have been shown

Received Dec. 21, 2012; revised May 7, 2013; accepted May 11, 2013.

Author contributions: H.H., F.W.-v.H., D.M., W.A.H., and C.E.H. designed research; H.H., F.W.-v.H., D.M., M.Z., and H.S. performed research; H.H. and F.W.-v.H. analyzed data; H.H., W.A.H., and C.E.H. wrote the paper.

This work was supported by Wellcome Trust Programme Grants (C.E.H., W.A.H), Biotechnology and Biological Sciences Research Council studentships (H.H, H.S), a Cambridge Gates Trust Scholarship (H.H), an EMBO fellowship (F.W.), the Deutsche Forschungsgemeinschaft (D.M.), the Studienstiftung des deutschen Volkes (H.S.), and a Wellcome Trust Ph.D. Studentship (M.Z.). We thank Larry Etkin (deceased) and his colleagues for the antibody to Hermes.

The authors declare no competing financial interests.

Correspondence should be addressed to Dr. Christine E. Holt, Department of Physiology, Development and Neuroscience, University of Cambridge, Downing Street, Cambridge CB2 3DY, United Kingdom. E-mail: ceh@mole.bio.cam.ac.uk.

DOI:10.1523/JNEUROSCI.5858-12.2013

Copyright $\odot 2013$ the authors $\quad 0270-6474 / 13 / 3310384-12 \$ 15.00 / 0$ to play a functional role in the response to guidance cues in both axons (Leung et al., 2006; Yao et al., 2006; Sasaki et al., 2010; Welshhans and Bassell, 2011) and dendrites (Perycz et al., 2011).

The Hermes RBPs (RBPMS and RBPMS2) are homologues of a highly conserved protein with one RNA recognition motif (RRM) domain in the C-terminal region. Hermes RBPs form messenger ribonucleoprotein (mRNP) complexes within the vegetal cortex in Xenopus and zebrafish oocytes (Zearfoss et al., 2004; Kosaka et al., 2007), and both the RRM domain and the $\mathrm{C}$-terminal portion of Hermes are required for binding of poly(A) + RNA in Xenopus (Gerber et al., 2002). A remarkable property of Hermes is its cell-specific expression pattern in the vertebrate CNS: it is expressed exclusively in the retinal ganglion cells (RGCs) of the eye in Xenopus, mouse, and rat (www.genepaint.org; Gerber et al., 1999; Piri et al., 2006; Kwong et al., 2010), suggesting that it may have an evolutionarily conserved specific function in these cells.

We investigated this idea in both Xenopus and zebrafish embryos and here show that Hermes protein is present in axons, growth cones, as well as the cell bodies of developing RGCs. Blocking Hermes function leads to a significant reduction of retinal axon arbor complexity in the tectum due to a decrease in arbor formation, rather than a decrease in arbor stability. Surprisingly, we found a corresponding increase in the density of presynaptic puncta and enhanced early visual behavior. This inverse relationship between arbor formation and functional synaptic density is suggestive of a homeostatic control mechanism that regulates the synaptic output of differentiating RGCs.

\section{Materials and Methods}

Embryos. Xenopus embryos of either sex were obtained by in vitro fertilization, raised in $0.1 \times$ modified Barth's saline at $14-20^{\circ} \mathrm{C}$, and staged according to the tables of Nieuwkoop and Faber (1967). Zebrafish 
(Danio rerio) embryos were obtained from wild-type (WT) AB and TL strains, mutant Lakritz strains, and $\operatorname{Tg}($ atoh7:gap43-RFP) (Zolessi et al., 2006) maintained and bred at $26.5^{\circ} \mathrm{C}$. Embryos were raised at $28.5^{\circ} \mathrm{C}$ in embryo medium supplemented with $0.003 \%$ phenylthiourea (Sigma) for pigment reduction. All animal work was approved by the local ethical review committee at the University of Cambridge and performed according to the protocols of Project License PPL 80/2198.

DNA constructs and morpholinos. All constructs used in this study were expressed in the pCS2 + vector (D. Turner, University of Michigan, Ann Arbor, MI). Xenopus hermes cDNA (GenBank GeneID AF107889) was kindly provided by M. Kloc (Methodist Hospital Research Institute, Houston, TX) and sublconed in pCS2+ with an N-terminal myc- or GFP-tag. Myc- and GFP-tagged RRM plasmids were then constructed by deleting bp 651-908 of the full-length hermes cDNA. Membrane GFP and RFP has been described previously (Das et al., 2003; Poggi et al., 2005). The Atoh7: Synaptophysin-RFP vector was kindly provided by L. Lagnado (University of Cambridge, Cambridge, UK). Antisense morpholinos (MOs) were obtained from Gene Tools. Xenopus hermes and control MOs were conjugated to FITC and were designed as described previously by Zearfoss et al., (2004). The Xenopus hermes_1 MO sequence was GCCCACCGAGGAGTCTGGCTTGTAC, and the Xenopus hermes_2-MO was ATGAGCGGCATCAAGTCAGACACGG. Zebrafish MO sequences were designed to target the start codons of hermes1a (rbpms2b, Danio rerio GenBank GeneID 393229; CTTGACACTCATCTTGTGCGTAAAC) and hermes $1 b$ ( rbpms2a, Danio rerio GenBank GeneID 436682; TTCAGACTCATTGTGTAACTTTAAC).

Plasmid and morpholino injection into zebrafish embryos. Sixteen nanograms of control MO (CoMO) or a mix of $8 \mathrm{ng}$ each of hermes1a and hermes $1 b \mathrm{MOs}(\mathrm{HeMO})$ were injected into the yolk of zebrafish embryos at the one- to two-cell stage. For visualization of single axons and synaptic puncta, embryos at the one cell stage were either injected with 5-10 pg of an atoh7:gapEGFP construct or coinjected with 5-10 pg atoh7:SynaptophysinRPF and atoh7:gapEGFP.

Xenopus embryo injection, electroporation, and lipofection. Embryos were injected as described previously (Vignali et al., 2000). Injections were performed at the eight-cell stage in both dorsal-animal blastomeres. HeMOs were injected at $2.5 \mathrm{ng}$ each and CoMOs at $5 \mathrm{ng}$. Capped mRNAs were synthesized from linearized plasmids using mMESSAGE mMACHINE kit (Ambion), and $0.5 \mathrm{ng}$ of myc-RRM mRNA or control myc mRNA was injected. RGC precursor cells were lipofected by pressure injecting the eye primordia of Stage 19 embryos with a mixture of mCherry cDNA $(1 \mu \mathrm{g} / \mu \mathrm{l})$ and lipofection reagent 1,2-bis-(oleoyloxy)-3-(trimethylammonium) propane (DOTAP; Boehringer) at 1:3 (w/v) (Holt et al., 1990; Lilienbaum et al., 1995). Embryos were electroporated as described previously (Falk et al., 2007). To target a large number of RGCs, $5 \mathrm{nl}$ of $1 \mu \mathrm{g} / \mu \mathrm{l}$ GFP-RRM, GAPGFP, mCherry, or RFP cDNA was injected into Stage 28 retinal primordium, followed by seven electric pulses ( $50 \mathrm{~ms}$ long) delivered at $18 \mathrm{~V}$. For scatter labeling, $5 \mathrm{nl}$ of $0.1-1.0 \mu \mathrm{g} / \mu \mathrm{l}$ DNA in water was injected into a Stage 28 retinal primordium, followed by a single electric pulse ( 25 $\mathrm{ms}$ long) delivered at $16 \mathrm{~V}$. Because cDNA constructs are expressed within $6 \mathrm{~h}$ of transfection (Holt et al., 1990), constructs electroporated into Stage 28 retinal primordia were expressed in axons pathfinding to the tectum (see Fig. 2D).

Retinal explant cultures. Whole retinas from Stage 35/36 embryos were placed on glass coverslips (Bellco) coated with poly-L-lysine $(10 \mu \mathrm{m}$ $\left.\mathrm{ml}^{-1}\right)$ and laminin $\left(10 \mu \mathrm{m} \mathrm{ml}^{-1}\right)$ and cultured for $24 \mathrm{~h}$ at $20^{\circ} \mathrm{C}$ in $60 \%$ L15 minimal medium (Invitrogen).

In situ hybridization. Embryos were fixed in 4\% paraformaldehyde/ PBS overnight. Whole-mount and section in situ hybridization (ISH) was performed as described by Concordet et al. (1996) and Mann et al. (2002). hermes probe sequences were complementary to the full length of the respective open reading frames.

Immunohistochemistry. For immunostaining, embryos were fixed in $4 \%$ paraformaldehyde/PBS overnight, washed extensively with PBS, permeabilized with $0.1 \%$ Triton X-100 and prepared for cryotome sectioning or whole-mount staining (Piper et al., 2006). Detection of Hermes protein expression was performed in zebrafish and Xenopus with a Hermes antibody (Eurogentec) raised in rabbit against the Hermes peptide AHFIARDPYDLTGAA (a gift from L. Etkin). The affinity-purified
Hermes antibody was used at a dilution of 1:4000 on cryotome sections $(10 \mu \mathrm{m})$ and visualized using Alexa Fluor 488- or 594-coupled secondary donkey anti-rabbit antibody (1:400; Invitrogen). Other primary antibodies were used as follows: zn5, 1:500 (Zebrafish International Resource Center); anti-acytelated tubulin, 1:500 (Sigma); anti-prox1, 1:200 (Millipore); anti-sox2, 1:200 (Millipore); anti-islet1, 1:50 (Developmental Studies Hybridoma Bank); and anti-activated-caspase-3, 1:500 (BD Pharmingen). Secondary antibodies were Cy3-coupled secondary goat anti-mouse antibody (1:400); Alexa Fluor 647 donkey anti-mouse antibody (1:400); and Alexa Flour 488, 594, and 647 donkey anti-rabbit (1:1000; Invitrogen). Twenty-four hour cultures of Stage 35/36 retinal explants positive for myc-RRM were immunostained as described previously (Piper et al., 2006; Drinjakovic et al., 2010) using mouse anti-Myc clone 9E10 antibody (Developmental Studies Hybridoma Bank) at a 1:2000 dilution.

Western blot analysis. Stage 32, 35/36, and 40 embryos' eyes were lysed in RIPA buffer (Sigma), resolved by 10\% SDS-PAGE, transferred to a nitrocellulose membrane (Bio-Rad), and subjected to Western blot analyses using a rabbit anti-Hermes peptide antibody (1:500) followed by an HRP-conjugated secondary antibody (Zymed) incubation and ECLbased detection (GE Healthcare).

Confocal imaging. For confocal imaging of Xenopus embryos, a Leica SP2 confocal microscope was used with either a $20 \times(0.45 \mathrm{NA})$ or a $63 \times$ (1.2 NA) water-immersion objective. Retinal arbors were reconstructed from 3D stacks of $1-\mu \mathrm{m}$-thick (for $20 \times$ ) or $0.4-\mu$ m-thick (for $63 \times$ ) images, with each image representing the average of three scans, using Leica Confocal Software. For imaging zebrafish embryos, a PerkinElmer Spinning Disk UltraVIEW ERS, Olympus IX81 inverted microscope, and $60 \times(1.2 \mathrm{NA})$ water-immersion objective were used. For time-lapse imaging, a motorized XY stage (H117; Prior) was used to image multiple embryos at the same time. Embryos were anesthetized in $0.4 \mathrm{mg} / \mathrm{ml}$ tricaine (Sigma) at appropriate stages aligned in custom-made observation dishes by embedding in $1 \%$ low-melting-point agarose in embryo medium. Confocal stacks had a spacing of $1 \mu \mathrm{m}$. Stacks were analyzed using the Volocity (Improvision) software package.

Analysis of RGC arbors. For analysis of axon arbor morphology in Xenopus, 3D projections of single axon arbors acquired at 63 or $40 \times$ were manually traced along the $z$-axis using OpenLab (Improvision). Zebrafish branch morphology was analyzed using Volocity (Improvision). As zebrafish arbors are mostly planar, we could perform arbor analysis on maximum-intensity projections of flattened images. The first branch point was used to set the boundary of the arbor. Processes smaller than $<5 \mu \mathrm{m}$ in length and/or $0.6 \mu \mathrm{m}$ in diameter were considered to be filopodia and excluded from the branching analysis. The arbor complexity index (ACI) was calculated according to Marshak et al., (2007) (see Fig. 2I). Total arbor length was measured by adding together the length of all branches of each arbor using the line tool in Volocity. For data presented in Figure 6, the confocal $z$-slice of each image was first cropped tightly around the axon using Volocity to remove signals not associated with that axon, followed by flattening into a maximum $z$-projection using Volocity. Total arbor area was measured by connecting the tips of all branches of each arbor using the freehand tool in Volocity. To measure axon length in the contralateral optic pathway, the distance from the optic chiasm to the distal tip of the labeled RGC axon projection was normalized to the distance from the optic chiasm to the posterior boundary of the dorsal tectum. Brain size was determined by normalizing the relative distance of the optic chiasm to the anterior versus the posterior border of the tectum. Presynaptic synaptophysin-RFP (syn-RFP) puncta per arbor were manually counted on maximum-intensity projections of unmanipulated flattened images. A punctum was defined as a local accumulation of syn-RFP larger than $0.5 \mu \mathrm{m}$ in diameter. All statistical analysis was performed using Prism (GraphPad) software.

Analysis of visual behavior. The optomotor response (OMR) assay was developed based on an assay described previously (Neuhauss et al., 1999). The test chamber was a $35 \times 20 \mathrm{~cm}$ glass dish with rounded edges, filled with E3 embryo medium. The dish was placed on a waterproof flat-screen thin-film-transistor (TFT) display (Protouch). The stimulus patterns were displayed with a Webkit browser (Apple 

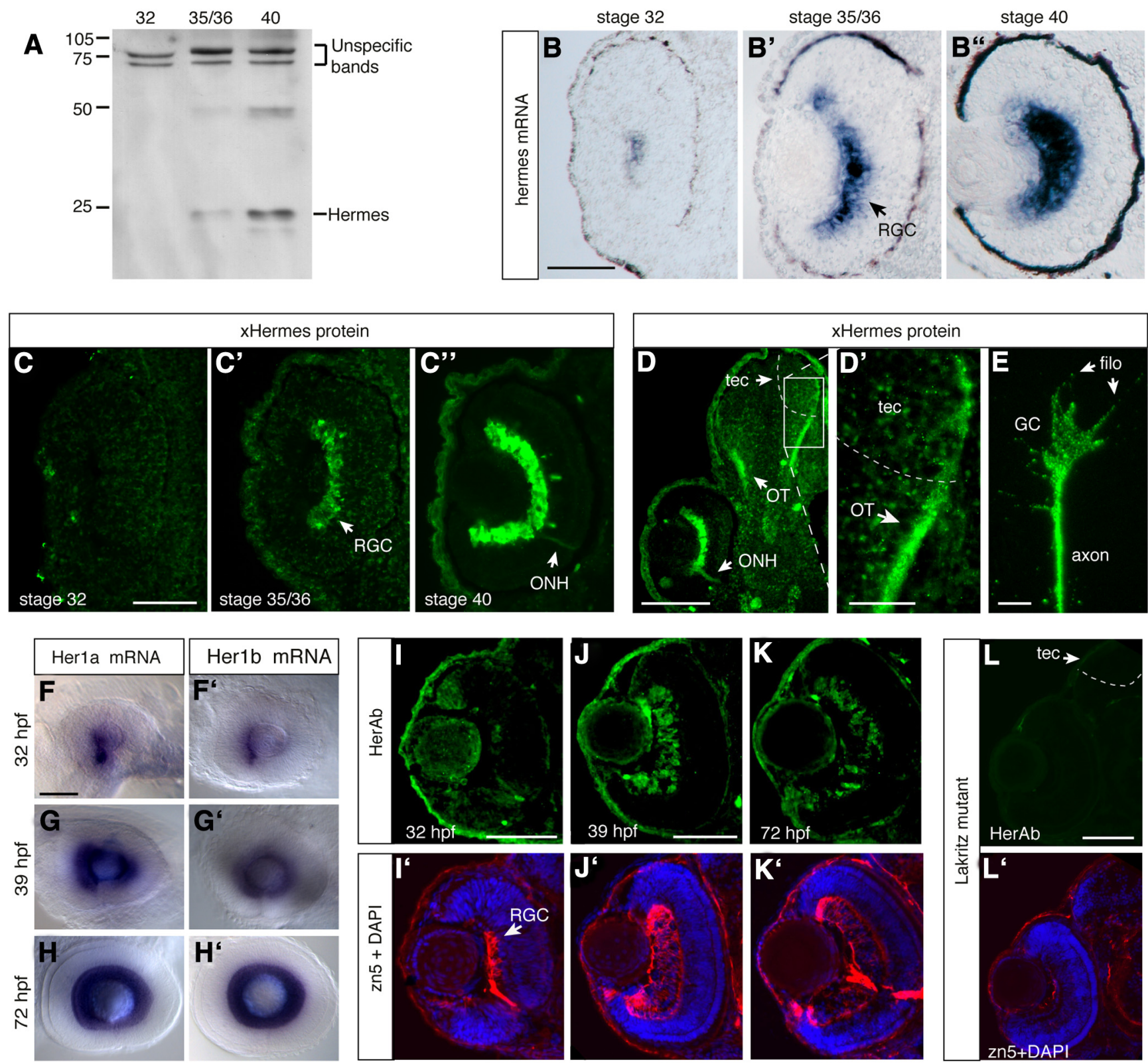

Figure 1. RGC-specific expression of Hermes in Xenopus and zebrafish. $A$, Western blot analysis of Xenopus embryo head lysates using an anti-Hermes antibody detects Hermes protein expression from Stage $35 / 36$ onward. $\boldsymbol{B}-\boldsymbol{B}^{\prime \prime}$, ISH staining of Xenopus retinal transverse sections shows that hermes signal in RGCs begins at Stage 32 ( $\boldsymbol{B}$ ) and increases progressively at $S$ tages $35 / 36\left(\boldsymbol{B}^{\prime}\right)$ and 40 $\left(\boldsymbol{B}^{\prime \prime}\right) . \boldsymbol{C}-\boldsymbol{C}^{\prime \prime}$, Immunostaining detects no Hermes protein expression at Stage $32(\boldsymbol{C})$ and a progressively stronger signal in RGCs at Stages $35 / 36\left(\boldsymbol{C}^{\prime}\right)$ and $40\left(\boldsymbol{C}^{\prime \prime}\right)$ in $X$ enopus retinal sections. $\boldsymbol{D}, \boldsymbol{D}^{\prime}$, Immunostained Hermes-positive RGC axons are visible in the $0 \mathrm{NH}$ in the retina $(\boldsymbol{C}, \boldsymbol{D})$, in the region of the $0 \mathrm{~T}(\boldsymbol{D})$, and tectum (tec) ( $\left.\boldsymbol{D}^{\prime}\right)$ in transverse sections through Xenopus brain at Stage 40 . $\boldsymbol{E}$, Immunostaining of Xenopus eye explants cultured at Stage $35 / 36$ for $24 \mathrm{~h}$ detects strong Hermes expression in growth cones and filopodia (filo). $\boldsymbol{F}$ - $\boldsymbol{H}^{\prime}$, Whole-mount ISH staining on embryonic zebrafish eyes shows that expression of both hermes genes (Her1a and Her1b) follows the wave of RGC differentiation, beginning at $32 \mathrm{hpf}\left(\boldsymbol{F}, \boldsymbol{F}^{\prime}\right.$ ) and progressing across the whole retina by 39 hpf $\left(\mathbf{G}, \boldsymbol{G}^{\prime}\right)$ and $72 \mathrm{hpf}\left(\boldsymbol{H}, \boldsymbol{H}^{\prime}\right) . \boldsymbol{I}-\boldsymbol{K}^{\prime}$, Zebrafish retinal sections coimmunostained for Hermes and zn5 (an RGC-specific marker), plus a DAPI nuclear stain, shows that Hermes protein colocalizes with zn5 staining at $32 \mathrm{hpf}\left(\boldsymbol{I}, \boldsymbol{I}^{\prime}\right), 39 \mathrm{hpf}\left(\boldsymbol{J}, \boldsymbol{J}^{\prime}\right)$, and $72 \mathrm{hpf}\left(\boldsymbol{K}, \boldsymbol{K}^{\prime}\right)$. $\boldsymbol{L}, \boldsymbol{L}^{\prime}$, Lakritz mutant section ( $\left.3.5 \mathrm{dpf}\right)$ coimmunostained for Hermes $(\boldsymbol{L})$ and zn5 and DAPI ( $\left.\boldsymbol{L}^{\prime}\right)$ shows no Hermes expression in eyes or brain of embryos lacking retinal ganglion cells. Scale bars: $\boldsymbol{A}-\boldsymbol{A}^{\prime \prime}, \mathbf{C}, \boldsymbol{D}, \boldsymbol{F}-\boldsymbol{H}^{\prime \prime}, 100 \mu \mathrm{m} ; \boldsymbol{D}^{\prime}, \boldsymbol{I}-\boldsymbol{L}^{\prime}, 50 \mu \mathrm{m} ; \boldsymbol{E}, 5 \mu \mathrm{m}$.

Safari) on the TFT screen. The stimulus projections were developed with Synchronized Multimedia Integration Language animated scalable vector graphics, a free and open standard defined by the World Wide Web Consortium (http://www.w3.org/Graphics/SVG/). Between 30 and 100 zebrafish larvae were placed in the chamber, where they were allowed to dark adapt on a black background in a dark room for $5 \mathrm{~min}$. Each trial consisted of a $30 \mathrm{~s}$ display of a motion pattern consisting of repeated black and white vertical bars with a width of 1.6 $\mathrm{cm}$ and velocity of $64 \mathrm{~mm} / \mathrm{s}$. After the trial, a white screen was displayed to record the embryo distribution with a digital camera. The next trial started by reversing the motion pattern. Each experimental data point is the average of three trials. For data analysis, each embryo in the target zone (defined as $20 \%$ of the test bowl at the end of the stimuli) was counted as a positive response and expressed as a percentage of the total number of fish in the trial.

\section{Results}

Hermes is expressed in differentiating retinal ganglion cells and their axons

Both Hermes genes are specifically expressed in the RGCs of the retina in several vertebrate species (www.genepaint.org) (Gerber et al., 1999; Piri et al., 2006; Kwong et al., 2010), suggesting an evolutionarily conserved function. To gain insight into the con- 

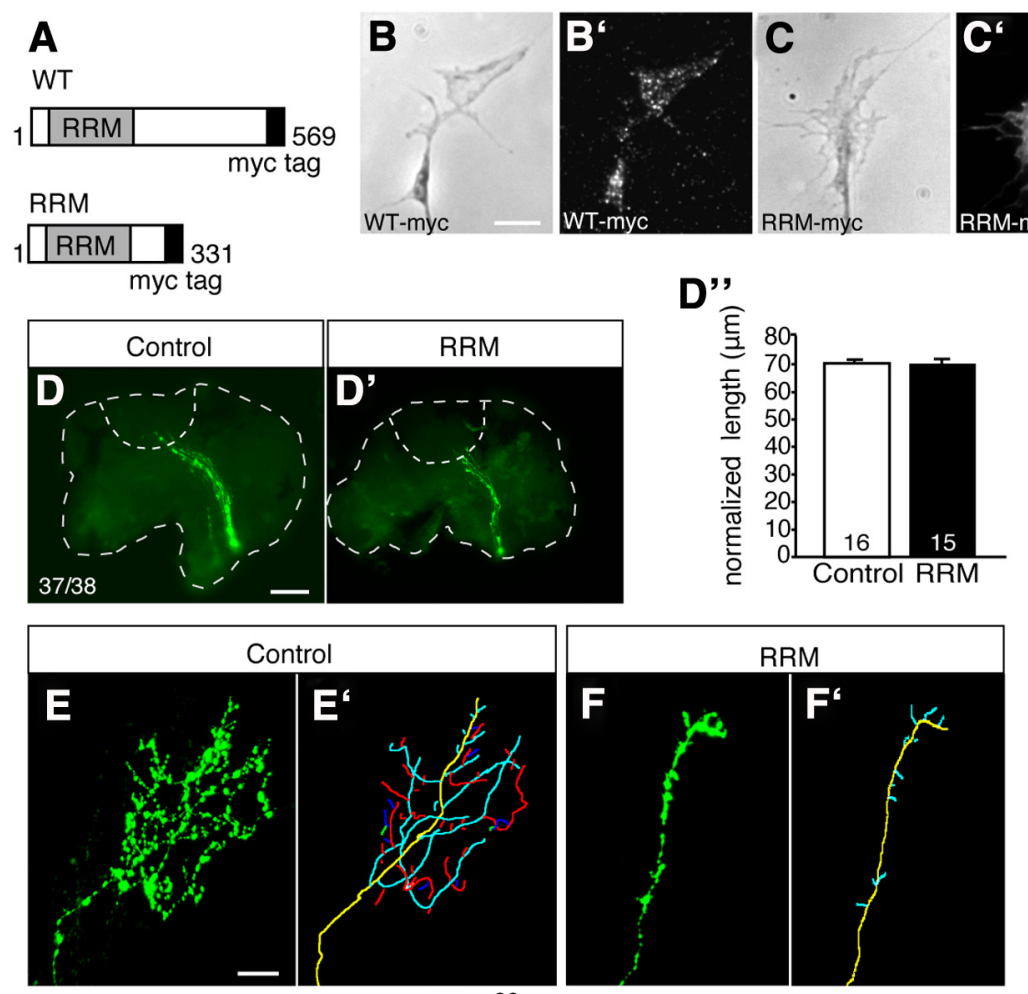

RRM

G
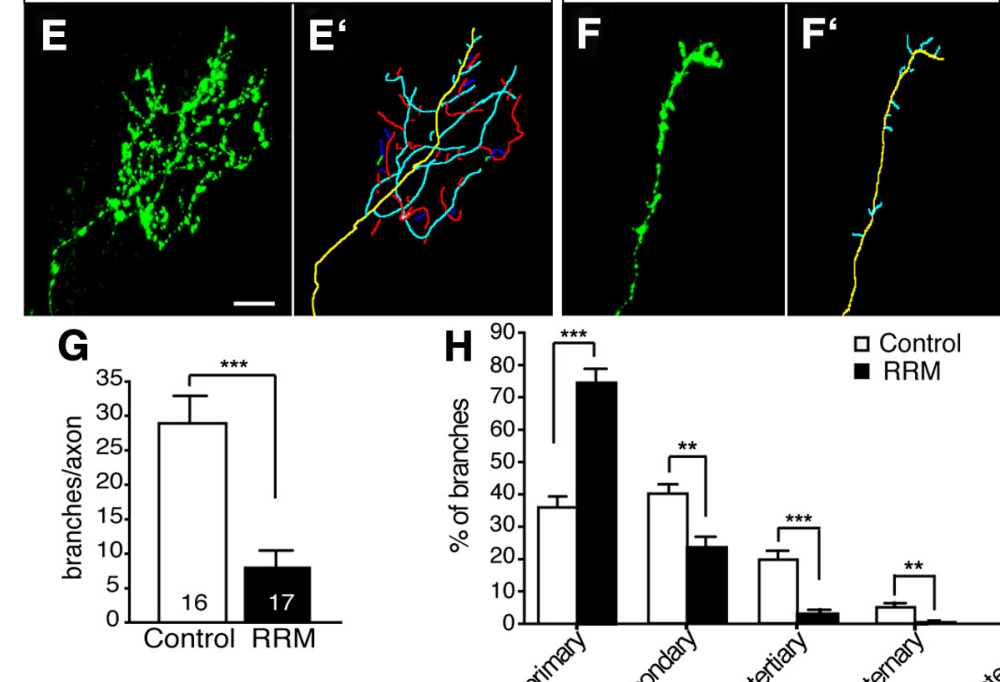

I

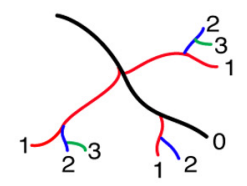

$$
\mathrm{ACl}=\frac{\begin{array}{c}
\Sigma \mathrm{N} \text { (branch order) } \mathrm{x} \\
\# \text { branches with order } \mathrm{N}
\end{array}}{\text { Total } \# \text { of branches }}
$$

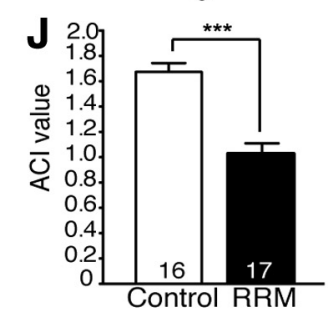

Figure 2. Hermes RRM-domain inhibits retinal axon branching in the tectum. $\boldsymbol{A}$, WT myc-Hermes or myc-RRM mRNA was injected into both blastomeres of two-cell stage Xenopus embryos. $\boldsymbol{B}-\boldsymbol{C}^{\prime}$, In retinal growth cones (cultured from mRNA-injected embryos at Stage 37/38 for $24 \mathrm{~h}$ ), the mutant and WT myc-tagged Hermes proteins localize differently: WT myc-Hermes $\left(\boldsymbol{B}, \boldsymbol{B}^{\prime}\right)$ is punctate, whereas myc-RRM $\left(\boldsymbol{C}-\boldsymbol{C}^{\prime}\right)$ is distributed smoothly within the cytosol. $\boldsymbol{D}-\boldsymbol{D}^{\prime \prime}$, Lateral views of Stage 37/38 whole-mount brains showing the GFP-labeled optic pathway of control- $(\boldsymbol{D})$ and RRM-injected embryos $\left(\boldsymbol{D}^{\prime}\right)$ showing no significant difference in the trajectory or the length of axon in the optic tract $\left(\boldsymbol{D}^{\prime \prime}\right) . \boldsymbol{E}-\boldsymbol{F}^{\prime}$, Single retinal axon terminal arbors in the tectum labeled with GFP at Stage 43 in control- $(\boldsymbol{E})$ and RRM-injected embryos $(\boldsymbol{F})$. The corresponding outlines of each terminal arbor are shown in $\boldsymbol{E}^{\prime}$ and $\boldsymbol{F}^{\prime}$, where branches of a different order are color coded: yellow, axon shaft; cyan, primary; red, secondary; blue, tertiary. $\boldsymbol{G}, \boldsymbol{H}$, RRM-expressing terminals show a significant decrease in total branch number $(\boldsymbol{G})$ and branches of all branch orders $(\boldsymbol{H})$. $\boldsymbol{I}, \boldsymbol{J}$, Comparing arbor complexity using the $\mathrm{ACI}(\boldsymbol{I})$ revealed a significant decrease in arbor complexity and a significant increase in the number of simple arbors $(\boldsymbol{J})$ in RRM-expressing embryos compared to control. Error bars represent SEM. ${ }^{* *} p<0.01 ;{ }^{* * *} p<$ 0.0001; Mann-Whitney test. The numbers of axons analyzed are indicated on the bars. Scale bars: (in $\boldsymbol{B}) \boldsymbol{B}-\boldsymbol{C}^{\prime}, 5 \mu \mathrm{m}$; (in $\left.\boldsymbol{D}\right) \boldsymbol{D}, \boldsymbol{D}^{\prime}$, $50 \mu \mathrm{m}$; (in $\boldsymbol{E}) \boldsymbol{E}-\boldsymbol{F}^{\prime}, 20 \mu \mathrm{m}$.

served role of Hermes, we therefore characterized Hermes expression and function in two evolutionary diverged vertebrate species, Xenopus laevis and zebrafish. The genome of Xenopus laevis, like humans, contains both paralogs of the Hermes genes (rbpms and rbpms2). The coding regions of the xHermes genes

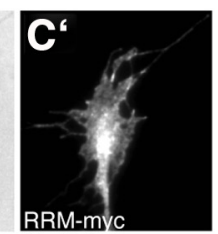

are $94 \%$ identical, and are therefore considered to encode functionally redundant proteins (Zearfoss et al., 2004). Zebrafish have just one Hermes gene (rbpms2) but in two versions, hermesla and hermes1b. Nucleotide alignment shows a $98 \%$ similarity, and the genes have identical expression patterns in the developing retina, suggesting that they also act redundantly. We hereafter refer to both proteins jointly as Hermes. To detect Hermes protein, we used an antibody raised against a conserved peptide in the Xenopus and zebrafish Hermes proteins (Zearfoss et al., 2004). This antibody detected two distinct bands on Western blots of Xenopus eye protein lysates (Fig. 1A), the lower band at $\sim 25 \mathrm{kDa}$ corresponding to the monomeric Hermes protein with a calculated molecular weight of $22 \mathrm{kDa}$. The upper band at $\sim 50 \mathrm{kDa}$ may indicate the presence of Hermes dimers, as reported by Gerber et al. (1999).

To gain insight into where Hermes might act in RGCs, we characterized its expression at both the RNA and protein levels during eye development in Xenopus and zebrafish (Fig. 1). ISH on Xenopus retinal sections revealed that hermes mRNA first appears in the RGC layer in the central retina at Stage 32, shortly after the onset of RGC differentiation (Fig. 1B). Further differentiation of the neural retina is accompanied by an increasingly stronger ISH signal in RGCs, extending from central to peripheral retina (Fig. $\left.1 B^{\prime}, B^{\prime \prime}\right)$.

The retinotectal map first forms at Stages 37/38-40 and, before this (Stages 32-37/38), RGC axons are navigating through the optic pathway (Grant and Rubin, 1980; Holt and Harris, 1983). Hermes protein is weakly detectable in eye lysates at Stage 35/36 (Nieuwkoop and Faber, 1967), but is much stronger at Stage 40, soon after RGC axons have entered the optic tectum (Fig. 1B). Immunostaining of Xenopus retina shows that Hermes protein is first detected at Stage $35 / 36$ (Fig. $1 C, C^{\prime}$ ), in agreement with the Western blot data (Fig. 1A), indicating that protein expression begins shortly after $(\sim 3 \mathrm{~h})$ the onset of mRNA transcription at Stage 32 (Fig. 1B). The intensity of Hermes immunoreactivity increases progressively with age, with stronger expression during the later stages of RGC development (Stage 40 ; Fig. $1 C-C^{\prime \prime}$ ), when RGC axons have begun to arborize and form synaptic connections in the tectum.

Immunostaining of cross-sections of Stage 37/38 Xenopus embryos revealed a positive signal in the optic nerve head $(\mathrm{ONH})$ and in the region of the optic tract (OT; Fig. $1 D, D^{\prime}$ ), suggesting 
A
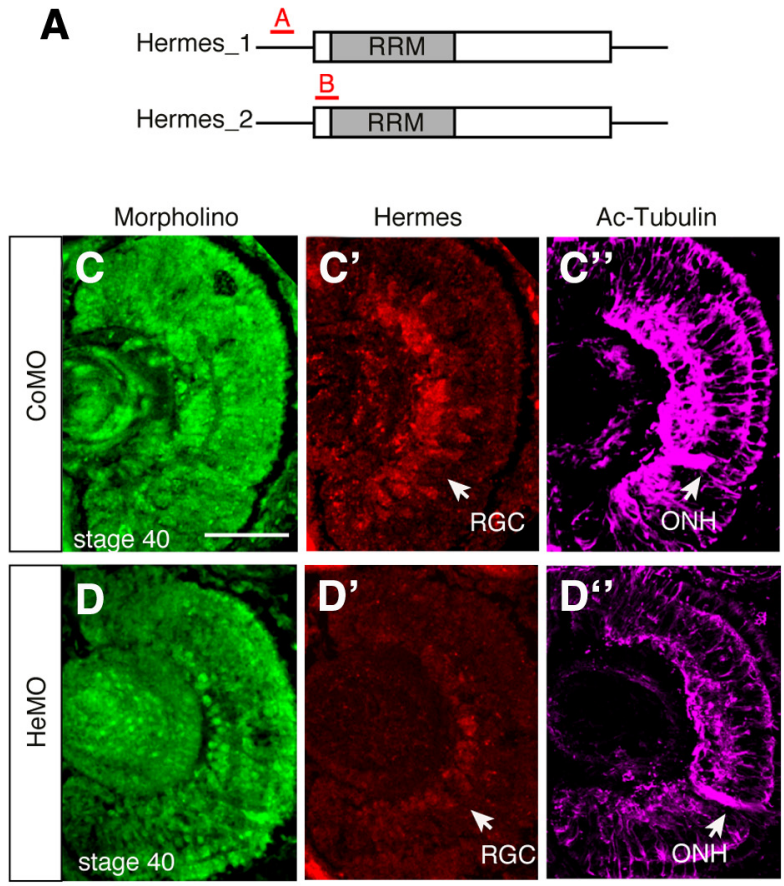

B

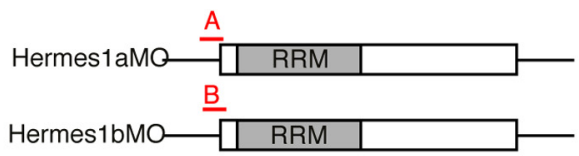

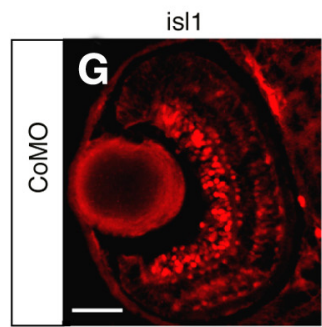

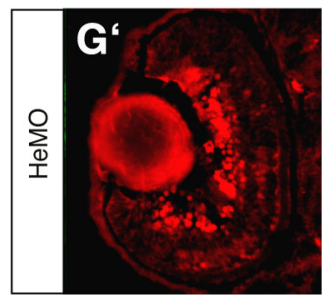

prox1
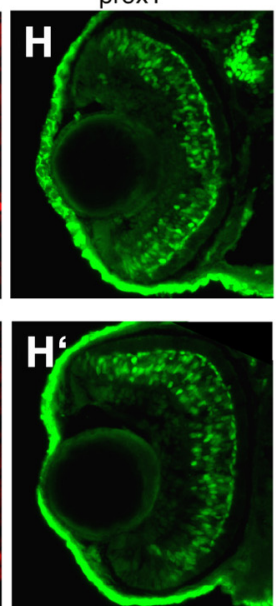

sox2
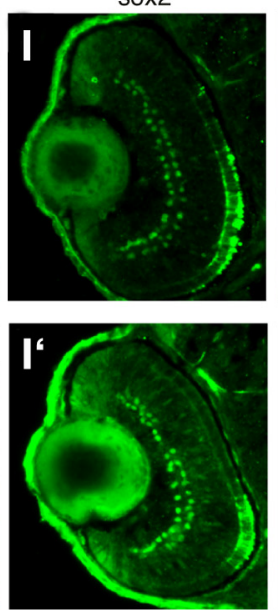

Hermes
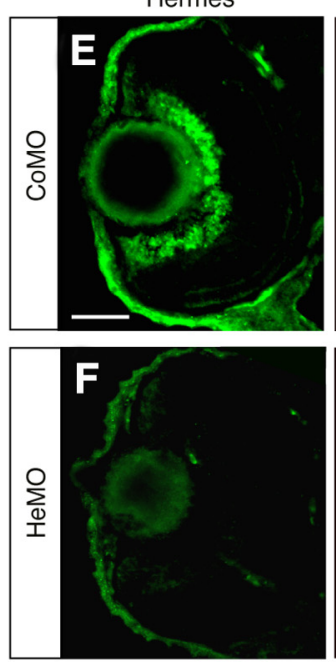

casp3

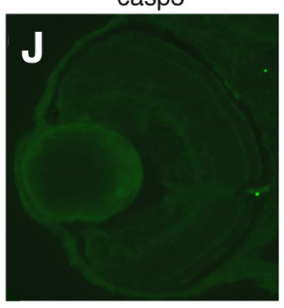

$J^{4}$

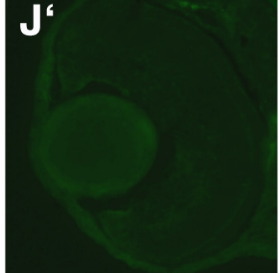

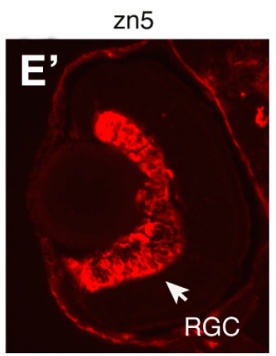
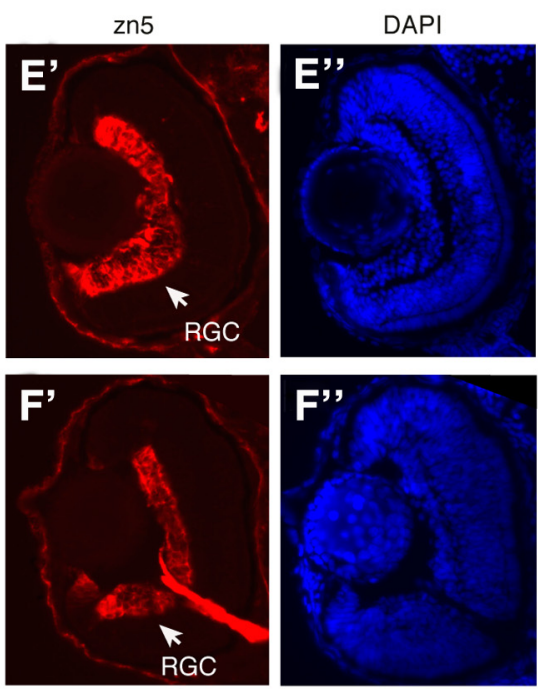

Figure 3. Hermes-depletion does not alter RGC specification and development. $\boldsymbol{A}, \boldsymbol{B}$, Translational blocking antisense MOs designed for Xenopus ( $\boldsymbol{A}$ ) and zebrafish ( $\boldsymbol{B}$ ) were used to knock down Hermes expression in the retina. $\boldsymbol{C}, \boldsymbol{D}$, Stage 40 retinal sections exhibit strong FITC-tagged MOs (green) signal throughout, indicative of robust intracellular loading following blastomere injections. $\boldsymbol{C}^{\prime}, \boldsymbol{C}^{\prime \prime}, \boldsymbol{D}^{\prime}, \boldsymbol{D}^{\prime \prime}$, M0-loaded Xenopus retinas coimmunostained for Hermes $\left(\boldsymbol{C}^{\prime}, \boldsymbol{D}^{\prime}\right)$ and Ac-tubulin $\left(\boldsymbol{C}^{\prime \prime}, \boldsymbol{D}^{\prime \prime}\right)$ show a severe loss of Hermes signal in the HeM0-loaded retina $\left(\boldsymbol{D}^{\prime}\right)$ compared to control $\left(\mathrm{CoM0} ; \boldsymbol{C}^{\prime}\right)$, but normal formation of the RGC layer and 0NH $\left(\boldsymbol{C}^{\prime \prime}, \boldsymbol{D}^{\prime \prime}\right)$. $\boldsymbol{E}-\boldsymbol{F}^{\prime \prime}$, Transverse sections of $56 \mathrm{hpf}$ CoM0 or HeM0 injected zebrafish embryos coimmunostained for Hermes $(\boldsymbol{E}, \boldsymbol{F})$, zn5 $\left(\boldsymbol{E}^{\prime}, \boldsymbol{F}^{\prime}\right)$,

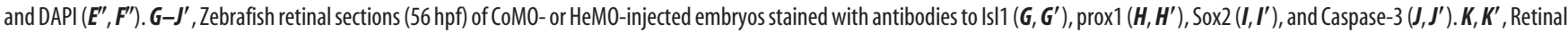
sections of atoh7:RFP transgenic CoM0-injected $(\boldsymbol{K})$ or HeM0-injected $\left(\boldsymbol{K}^{\prime}\right)$ zebrafish embryos showing RGC dendrite sublamination in the IPL at $5 \mathrm{dpf}$. Scale bars: (in $\left.\boldsymbol{C}, \boldsymbol{E}, \boldsymbol{G}\right) \boldsymbol{C}-\boldsymbol{J}^{\prime}, 100 \boldsymbol{\mu}$; ; $($ in $\boldsymbol{K}$ ) $\boldsymbol{K}, \boldsymbol{K}^{\prime}, 25 \mu \mathrm{m}$.

that Hermes protein is transported into RGC axons. To verify this, immunohistochemistry was performed on Stage 35/36 retinal cultures (cultured for $24 \mathrm{~h}$, equivalent to Stage 41 in vivo), where single axons can be visualized. RGC axons and growth cones exhibited punctate immunostaining (Fig. 1E), reminiscent of RNP particles (Kiebler and Bassell, 2006). The signal localized to both the central and peripheral domains of growth cones and often extended into filopodia (Fig. 1E). These data indicate that Hermes, potentially along with its target mRNA cargo, is trafficked to the tips of retinal axons.

In zebrafish, hermes expression in the retina also follows the differentiation of RGCs from an early stage [ $32 \mathrm{~h}$ postfertilization (hpf); Fig. $\left.1 F, F^{\prime}\right]$. A developmental ISH series of both hermes $1 a$ and $1 b$ performed on whole-mount eyes shows that hermes expression starts in a ventronasal patch of the retina and expands during the subsequent $24 \mathrm{~h}$ in a wavelike pattern across the retina, similar to the onset and differentiation pattern of RGC progenitors during the same time period (Fig. $\left.1 F-H^{\prime}\right)$ (Hu and Easter, 1999; Neumann and NuessleinVolhard, 2000). Immunocytochemistry shows that Hermes protein expression follows the exit of RGCs from the cell cycle with a delay of only a few hours in zebrafish (Fig. $\left.1 I-K^{\prime}\right)$, as in Xenopus.

Since the onset of hermes mRNA expression occurs early during RGC differentiation, we tested whether hermes expression is dependent on RGC differentiation. In the zebrafish 

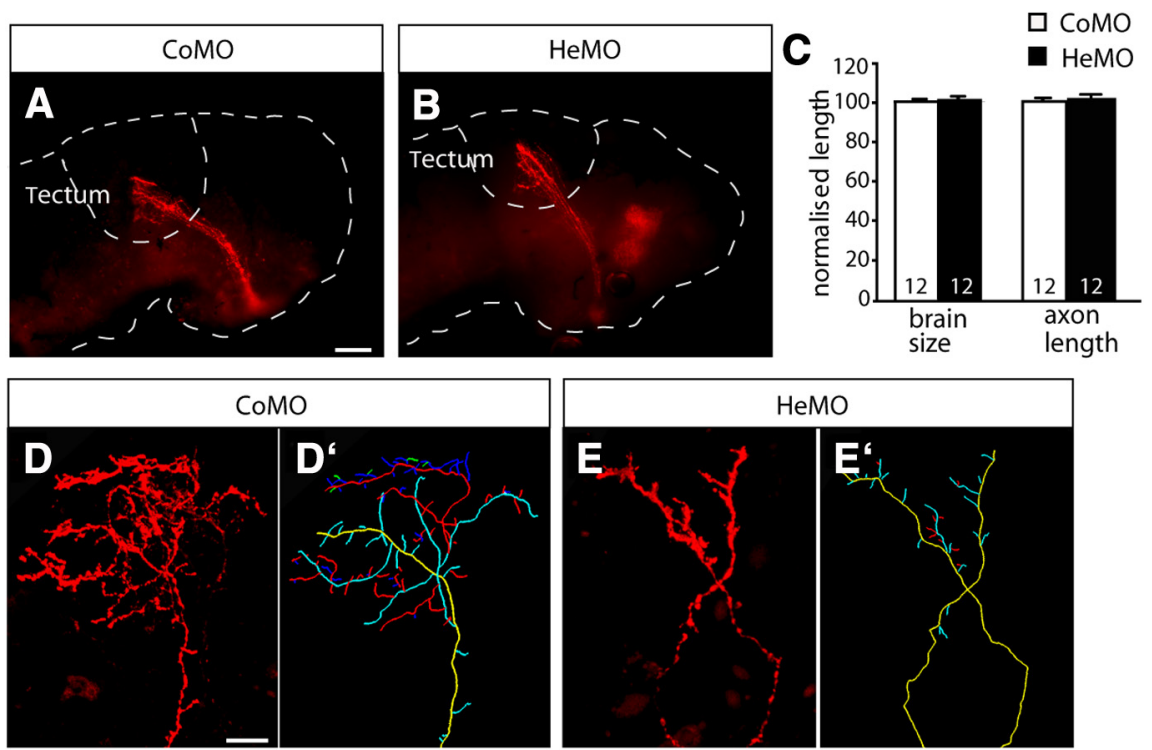

HeMO

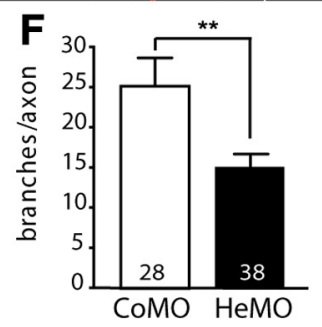

G
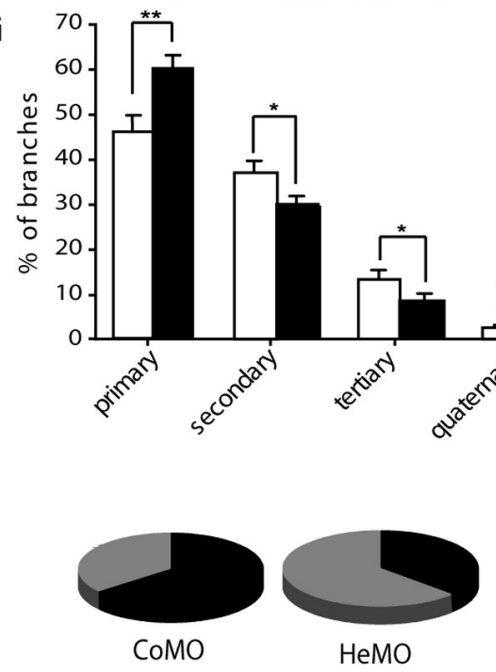

complex arbors $\square$ simple arbors
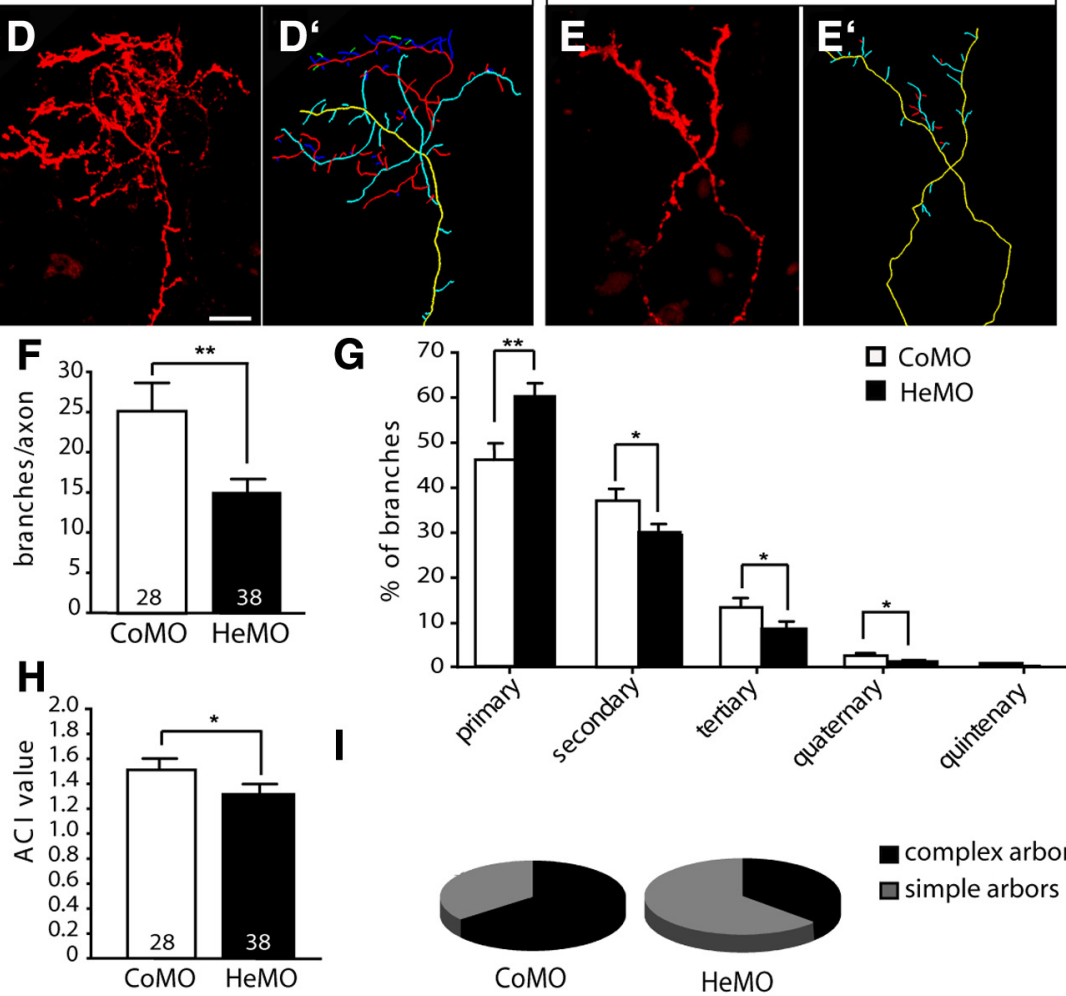

Figure 4. Hermes knockdown inhibits axonal branching in Xenopus. $\boldsymbol{A}-\boldsymbol{E}$, Embryos were blastomere injected with CoM0 or HeM0 and fixed at Stage 43. RGC axons labeled by eye-targeted RFP electroporation at Stage 28. Lateral view of whole-mount brains showing RFP-labeled retinotectal projections in CoMO- $(\boldsymbol{A})$ and HeM0-injected embryos $(\boldsymbol{B})$. There are no significant defects in long-range guidance, brain size, or axon length (C). Single RFP-labeled retinal axon terminals are highly branched in CoM0injected embryos $(\boldsymbol{D})$, but only sparsely branched in HeM0-injected $(\boldsymbol{E})$ embryos. The corresponding outlines of each terminal arbor are shown in $\boldsymbol{D}^{\prime}$ and $\boldsymbol{E}^{\prime}$, where branches of a different order are color coded: yellow, axon shaft; cyan, primary; red, secondary; blue, tertiary. $\boldsymbol{F}-\boldsymbol{I}$, Hermes depletion leads to a significant reduction in average number of branches per axon $(\boldsymbol{F})$, percentage of branches at all branch orders $(\boldsymbol{G})$, and arbor complexity $(\boldsymbol{H}, \boldsymbol{I})$. Simple arbors, $\mathrm{ACl}<1.4$; complex arbors, $\mathrm{ACl} \geq 1.4$. Error bars representSEM. ${ }^{*} p<0.05 ;{ }^{* *} p<0.01$; Mann-Whitney test. The numbers of projections $(\boldsymbol{C})$ or axons $(\boldsymbol{D}-\boldsymbol{I})$ analyzed are indicated on the bars. Scale bars: (in $\boldsymbol{A}) \boldsymbol{A}, \boldsymbol{B}, 50 \mu \mathrm{m}$; (in $\boldsymbol{D}) \boldsymbol{D}-\boldsymbol{E}^{\prime}, 20 \mu \mathrm{m}$.

lakritz/atoh7 mutant, RGCs fail to differentiate (Kay et al., 2001), and in the mouse, hermes expression is downregulated in atoh7 knock-outs (Mu et al., 2005). We found a complete loss of Hermes protein in lakritz fish (Fig. $1 L-L^{\prime \prime}$ ), consistent with RGC-specific expression.

\section{Hermes RNA binding domain interferes with axonal branching}

To investigate whether Hermes plays a role in RGC axon development, we first disrupted Hermes function in Xenopus by expressing a myc-tagged C-terminal truncated Hermes construct lacking amino acids 111-189, but still containing the N-terminal RNA binding RRM domain (Fig. 2A). Since the RRM domain binds to mRNA, this truncated Hermes protein (RRM) is pre- dicted to act as a dominant negative, as it should still bind target mRNA(s) but lack other essential functions such as transport and localization. Consistent with this, the RRM-myc deletion mutant shows an altered pattern of subcellular distribution (Fig. 2B-C' ). While the myc-tagged WT Hermes exhibits a punctate granular distribution in the axon and growth cone (Fig. $2 B^{\prime}$ ), the myc-tagged RRM domain is not punctate, but dispersed throughout the cytosol of the axon and growth cone (Fig. 2 $C^{\prime}$ ).

To assess whether the expression of RRM caused an axonal phenotype in vivo, we electroporated an eGFP-tagged RRM (eGFP-RRM) construct into the eye primordium of Stage 26 embryos (Falk et al., 2007) and subsequently analyzed the optic projection at Stage 43, when the axons have reached the tectum and started to branch. The trajectory of axons along the pathway (optic tract) to the tectum was normal (Fig. $2 D, D^{\prime}$ ), indicating that the long-range guidance of RGC axons to the tectum was unaffected. Nor was there any delay in axonal growth, as the length of RRM-expressing axons did not differ from controls at Stage 37/38 (control, $70.7 \pm$ 0.9\%; RRM, $70.2 \pm 1.3 \%$; $p>0.05$, MannWhitney test; Fig. $2 D^{\prime \prime}$ ). Similar results were obtained with a C-terminal GFP-tagged RRM construct, showing that the position of the GFP-tag does not affect the result.

RRM-expressing retinal axon terminals in the tectum (Stage 43) show a severe reduction in arbor complexity (Fig. 2E$F^{\prime}$ ). Quantification revealed that the number of branches per axon was reduced from $29( \pm 4)$ in control GFP-expressing axons to $8( \pm 2)$ in eGFP-RRM axons $(p<$ 0.0001, Mann-Whitney test; Fig. 2G). The proportional reduction in branch number is most pronounced in branches of higher order, with tertiary branches only making up $8.8 \%$ of the total amount of branches in RRM-expressing embryos, compared to $13.8 \%$ in control, and quaternary branches being reduced by $>60 \%$ (Fig. $2 \mathrm{H})$. The complexity of the arbors was measured by calculating the ACI (Fig. 2I) (Marshak et al., 2007). The ACI for RRMexpressing embryos confirmed a highly significant reduction in the complexity of axonal arbors compared to control embryos $(p<$ 0.0001 , Mann-Whitney test; Fig. $2 J$ ). The reduced complexity of RRM-expressing axons is particularly striking when dividing the arbors into complex $(>1.4)$ and simple arbors $(<1.4)$, showing that $88 \%$ of all arbors are simple or unbranched, compared to only $19 \%$ in control embryos (Fig. $2 K$ ).

\section{Morpholino knockdown of Hermes inhibits axonal branching}

As RRM domains are found in multiple RNA-binding proteins, the above-described approach may not demonstrate a specific 
role of Hermes in regulating branching. We therefore targeted Hermes for knockdown using translation blocking antisense morpholinos against either Xenopus or zebrafish Hermes genes. Translation MOs were designed against both hermes 1 and 2 for Xenopus (Fig. 3A) and hermes $1 a$ and hermes $1 b$ for zebrafish (Fig. $3 B$ ). In Xenopus, we injected $5 \mathrm{ng}$ of FITC-labeled HeMO (2.5 ng of each) or CoMO at the eight-cell stage and let the embryos develop to Stage 35/36 or Stage 40 (Fig. $3 C, D)$. Immunostaining of retinal sections in these embryos revealed an almost complete absence of Hermes signal at Stage 40 in HeMO-, but not in CoMOinjected embryos, confirming the efficacy of the HeMO (Fig. $3 C^{\prime}, D^{\prime}$ ). At this concentration, neither HeMO nor CoMO had any adverse effects on early axon outgrowth as assessed by acetylated tubulin staining on eye sections of Stage 40 morpholino-injected embryos (Fig. $\left.3 C^{\prime \prime}, D^{\prime \prime}\right)$. Similarly, injection of $16 \mathrm{ng}$ HeMO (8.0 ng each of $1 \mathrm{a}$ and $1 \mathrm{~b}$ ) into one-cell zebrafish embryos reduced Hermes staining in the retina (Fig. $3 E, F$ ) without altering expression of the RGC marker zn5 (Fig. $3 E^{\prime}, F^{\prime}$ ) or retina morphology (Fig. $3 E^{\prime \prime}, F^{\prime \prime}$ ). To determine whether neural differentiation was affected, we investigated the expression of several retinal cell differentiation markers for aberrant expression in zebrafish embryos. For prox1 (horizontal cells), islet1 (RGC, horizontal and biopolar cells), and sox2 (amacrine cells), no significant delays or changes in expression pattern could be observed in HeMO versus CoMOinjected retinas (Fig. 3G-I'). Furthermore, staining with an antiactivated caspase- 3 antibody indicated no increase in apoptosis in morphant retinas (Fig. $\left.3 J, J^{\prime}\right)$. The dendrites of RGCs laminate in the inner plexiform layer (IPL). To determine whether RGC dendrite formation and lamination was disrupted in Hermesdepleted embryos, we used a transgenic zebrafish line that expressed RFP under the atoh7 promoter (Zolessi et al., 2006), thereby strongly labeling all RGCs and their dendrites. In $5 \mathrm{~d}$ postfertilization (dpf) embryos, we observed no gross abnormalities in outgrowth or lamination pattern of RGC dendrites in the IPL in Hermes-depleted embryos compared to control-injected embryos (Fig. $3 K, K^{\prime}$ ).

To visualize single RGC axons for arborization analysis in morpholino-injected Xenopus embryos, mCherry or RFP was electroporated at Stage 26 or lipofected at Stage 19 into MOpositive retinas. Embryos were then allowed to develop until Stage 43 for analysis. Both approaches, as in RRM-injected embryos, showed that long-range axon pathfinding was unaffected in HeMO compared to CoMO-injected embryos (Fig. 4A,B). Moreover, no change in normalized brain size or axon bundle length

E $\mu \mathrm{m}$; (in $C)\left(-D^{\prime}, 20 \mu \mathrm{m}\right.$.
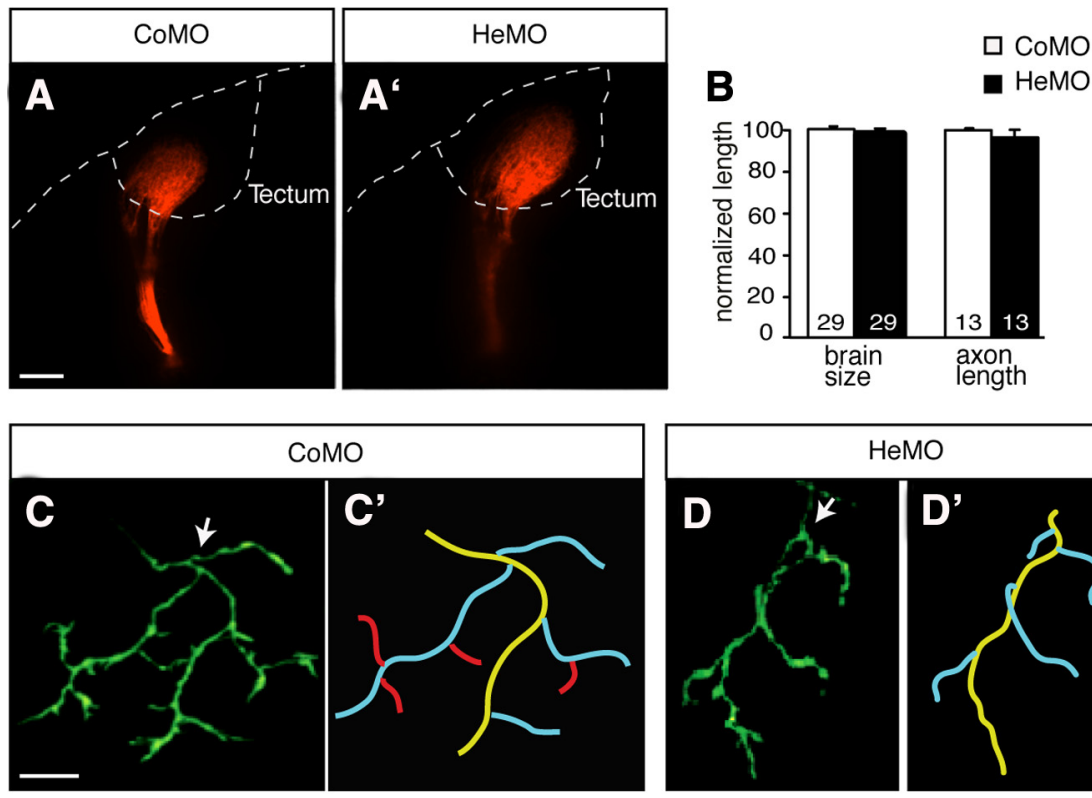

HeMO

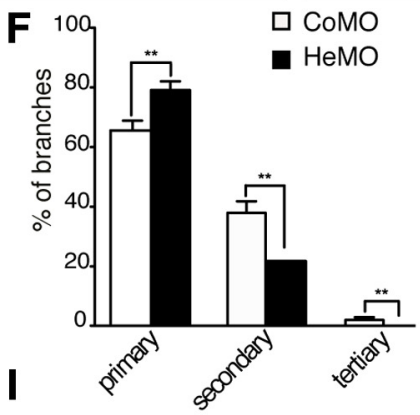

G
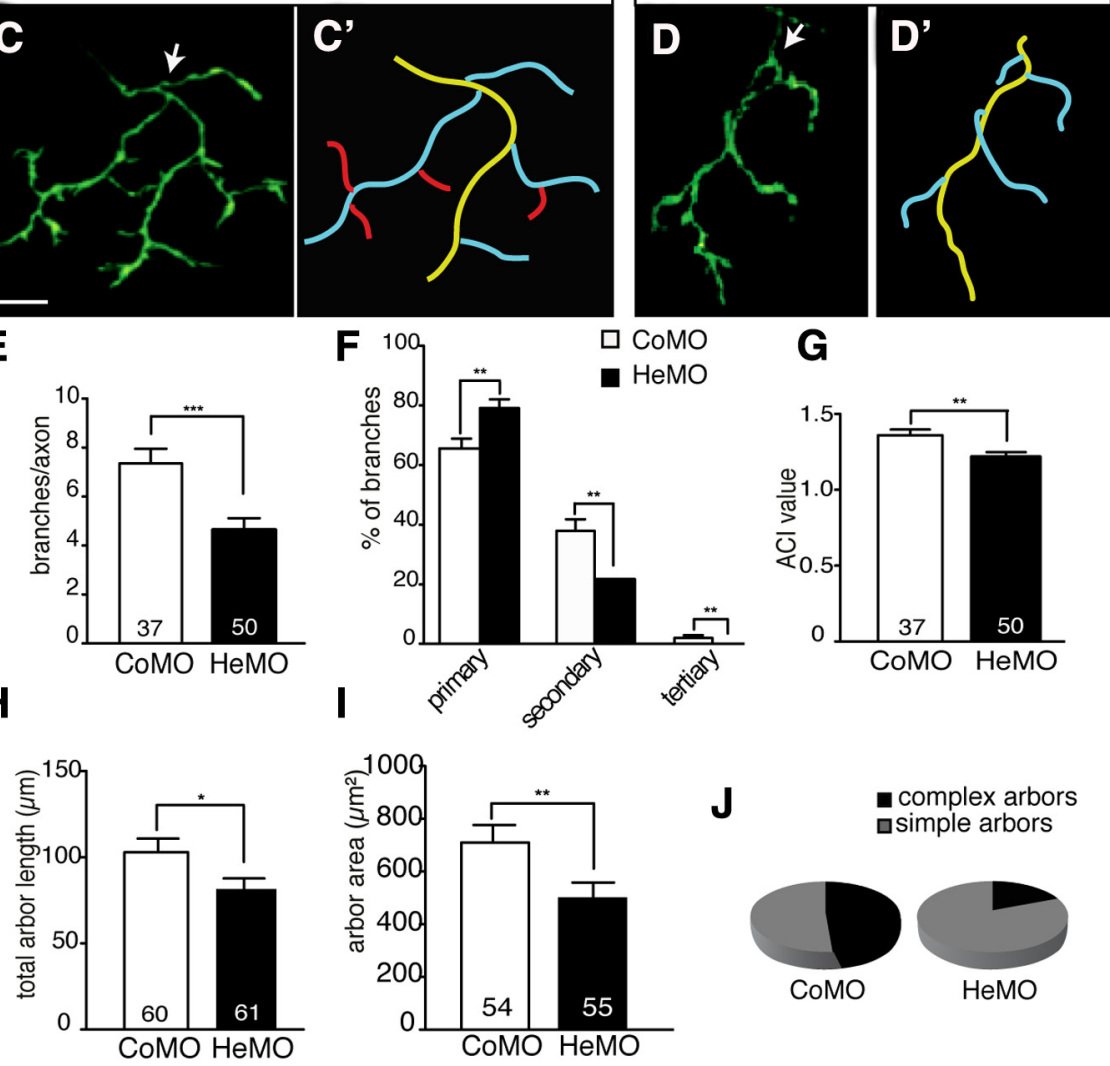

J

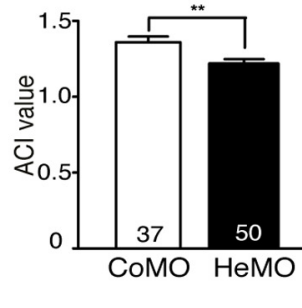

Figure 5. Hermes knockdown inhibits axonal branching in zebrafish. $A-B$, Embryos were injected with either CoM0 or HeMO and fixed at $5 \mathrm{dpf}$ followed by anterograde Dil labeling of RGC axons. Control- $(\boldsymbol{A})$ and HeMO-injected embryos $\left(\boldsymbol{A}^{\prime}\right)$ at $5 \mathrm{dpf}$ show o difference in long-range axon guidance, brain size, or axon length $(\boldsymbol{B})$. $\left(-\boldsymbol{D}^{\prime}\right.$, Control- $(\boldsymbol{C})$ or HeM0-injected embryos $(\boldsymbol{D})$ were injected with eGFP to label single axons and are shown in whole-mount views of the tectum at $4 \mathrm{dpf}$, with corresponding tracings of arbor outlines in $\boldsymbol{C}^{\prime}$ and $\boldsymbol{D}^{\prime}$. $\boldsymbol{E}$-J, HeM0-injected embryos show a significant reduction in total number of branches per axon $(\boldsymbol{E})$, arbors $(\boldsymbol{J})$. Simple arbors, $\mathrm{ACl}<1.4$; complex arbors, $\mathrm{ACl} \geq 1.4$. Error bars represent SEM. ${ }^{*} p<0.05$; ${ }^{* *} p<0.01$; ${ }^{* * *} p<0.001$; Mann-Whitney test. The numbers of embryos $(\boldsymbol{B})$ and axons $(\boldsymbol{E}-\boldsymbol{J})$ analyzed are indicated on the bars. Scale bars: (in $\boldsymbol{A}) \boldsymbol{A}, \boldsymbol{A}^{\prime}, 50$

was observed (Fig. 4C). Strikingly, we found that axonal branching was significantly compromised upon Hermes knockdown (Fig. 4D-E'). The branch number of Hermes-depleted axons was significantly reduced to $15( \pm 1.3)$ compared to $25( \pm 3.3)$ branches per axon in control embryos $(p<0.01$, Mann-Whitney test; Fig. $4 F$ ). The reduction in arbor complexity is evident on all branch orders, leading to a proportional reduction of secondary, tertiary, and quaternary branches (Fig. 4G). Reduction in axonal arbor complexity is also reflected by a significant reduction in the ACI of HeMO-injected embryos $(1.33 \pm 0.04)$ compared to control embryos ( $1.51 \pm 0.07 ; p<0.05$, Mann-Whitney test; Fig. $4 H$ ), and when comparing the number of complex axon arbors 

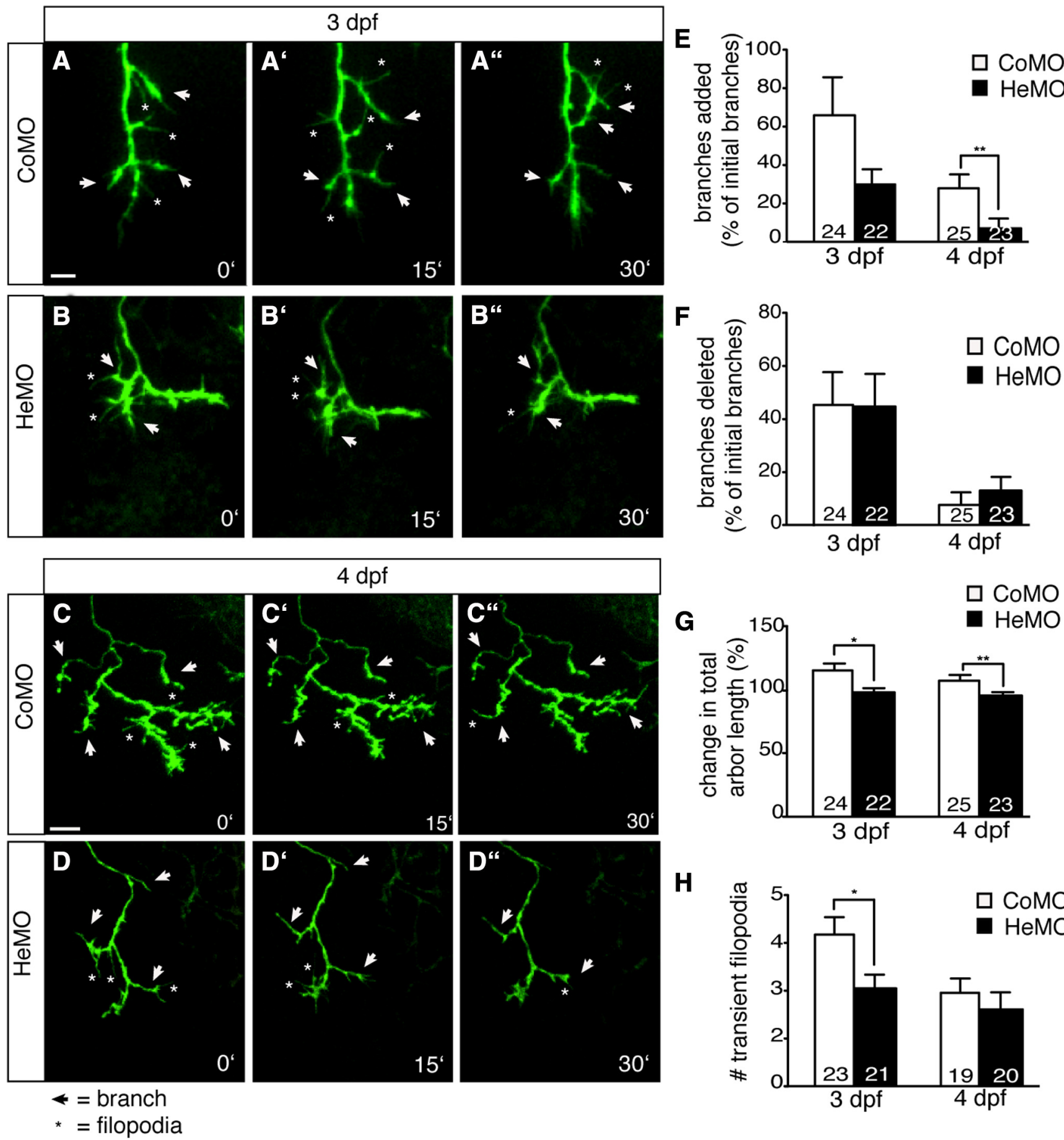

H

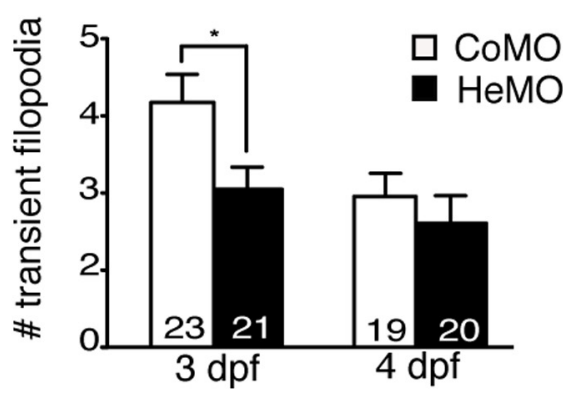

Figure 6. Hermes knockdown alters branch dynamics. $\boldsymbol{A}-\boldsymbol{D}^{\prime \prime}$, GFP-labeled retinal axon arbors of HeMO- or CoM0-injected embryos were imaged every $15 \mathrm{~min}$ for $30 \mathrm{~min}$ at $3 \mathrm{dpf}\left(\boldsymbol{A}-\boldsymbol{B}^{\prime \prime}\right)$ and 4 $\operatorname{dpf}\left(\boldsymbol{C}-\boldsymbol{D}^{\prime \prime}\right)$. $\boldsymbol{E}-\boldsymbol{G}$, HeM0-injected embryos added fewer branches at both 3 and $4 \mathrm{dpf}$, significantly at $4 \mathrm{dpf}(\boldsymbol{E})$, with no difference in the percentage of deleted branches $(\boldsymbol{F})$. Hermes morphants showed a significant decrease in total arbor length at both 3 and $4 \mathrm{dpf}(\boldsymbol{G})$ and a decrease in transient filopodia at $3 \mathrm{dpf}(\boldsymbol{H})$ compared to control-injected embryos. Error bars represent SEM. ${ }^{*} p<$ 0.05 ; ** $p<0.01$; Mann-Whitney test. The numbers of axons analyzed is indicated on the bars. Scale bars: $10 \mu \mathrm{m}$.

$(>1.4)$ and simple arbors $(<1.4)$ in CoMO- and HeMO-injected embryos (Fig. 4I).

Injection of HeMO in zebrafish embryos did not affect longrange guidance (Fig. 5A, $A^{\prime}$ ), brain size, or axon length (Fig. $5 B$ ), as in Xenopus. To visualize individual arbors in the tectum, embryos were coinjected with an atoh7:GAPGFP reporter construct (see Materials and Methods) and allowed to develop until $4 \mathrm{dpf}$. Similar to observations in Xenopus embryos, HeMO-injected embryos showed a significant reduction in axonal branching in the tectum compared to control-injected embryos (Fig. 5C- $D^{\prime}$ ). The number of axonal RGC branches was significantly reduced compared to control embryos (control, $7.35 \pm 0.604$; HeMO, $4.64 \pm 0.477 ; p<0.0001$, Mann-Whitney test; Fig. $5 E$ ), and the reduction was significant in arbors of all branch orders (Fig. $5 F$ ). The decrease in axonal branching is also reflected by a reduction of the ACI in Hermes morphants (control, $1.36 \pm 0.036$; HeMO, $1.21 \pm 0.03 ; p<0.01$, Mann-Whitney test; Fig. $5 G$ ), and when comparing the percentage of complex and simple arbors (Fig. 
5J). Furthermore, there was a significant reduction of total arbor length (control, $102.9 \pm 7.3$; HeMO, 81.6 $\pm 6.2 ; p<0.05$, Mann-Whitney test; Fig. $5 \mathrm{H}$ ) and total arbor area (control, $709.7 \pm 63.7 ; \mathrm{HeMO}$, $501.5 \pm 56.7 ; p<0.001$, Mann-Whitney test, Fig. 5I) in the Hermes morphants compared to control embryos, which correlates well with the observed reduction in branch number and complexity. Together with the Xenopus data, these results strongly suggest that Hermes plays a consistent and conserved role as a positive regulator of axon arborization in the optic tectum.

\section{Branch formation is reduced in Hermes morphants}

Axonal branching is a highly dynamic process, characterized in zebrafish by an early phase of branches rapidly extending and retracting, followed by a later, more stable phase with less dynamic arborization (Stuermer, 1988; Campbell et al., 2007). To investigate how Hermes depletion affects branch dynamics, we performed time-lapse imaging of GFPlabeled axons at $3 \mathrm{dpf}$ (high branch dynamics) and $4 \mathrm{dpf}$ (low branch dynamics) in zebrafish embryos at 15 min intervals for $30 \mathrm{~min}$. As reported previously (Stuermer, 1988; Campbell et al., 2007), axons of control-injected embryos display a highly dynamic pattern, with new branches being added and retracted during the $30 \mathrm{~min}$ time span at $3 \mathrm{dpf}$ (Fig. $\left.6 A-A^{\prime \prime}\right)$, whereas less dynamic changes are observed at $4 \mathrm{dpf}$ (Fig. $\left.6 C-C^{\prime \prime}\right)$. To investigate whether the reduction in total branch number observed in the Hermes morphants is due to a change in branch dynamics, we analyzed the branches being added and retracted, respectively, during a $30 \mathrm{~min}$ period. At both 3 and $4 \mathrm{dpf}$, Hermes morphants added both a smaller number and a smaller percentage of branches compared to the number or branches at the start time than control embryos, although this trend was significant only at $4 \mathrm{dpf}$ (Fig. 6A-E). This reduced rate of branch addition leads to reduced growth in total arbor length at both $3 \mathrm{dpf}$ (control, $114.7 \pm$ 6.3\%; HeMO, 97.6 \pm 4.3\%, $p<0.05$, Mann-Whitney test; Fig. $6 G$ ) and $4 \mathrm{dpf}$ (control, $106.8 \pm 3.9 \%$; HeMO, $95.1 \pm 3.7 \%$; $p<0.01$, Mann-Whitney test; Fig. $6 G$ ). Hermes-depleted embryos also show a reduction of transient filopodia that is significant at $3 \mathrm{dpfbut}$ not at $4 \mathrm{dpf}($ Fig. $6 H$ ). Interestingly, there was no difference in the percentage of retracted branches (Fig. $6 A-D^{\prime}, F$ ) so an RGC axonal branch once formed in a Hermes morphant RGC has the same chance of surviving for $30 \mathrm{~min}$ as a branch from a control RGC. These results suggest that branch initiation and formation is reduced by Hermes depletion, but branch stability is not.

Synaptic density is increased in Hermes-depleted embryos Synapse formation and arborization occur during the same developmental time frame (Alsina et al., 2001; Meyer and Smith, 2006), and many branch-regulating molecules, such as
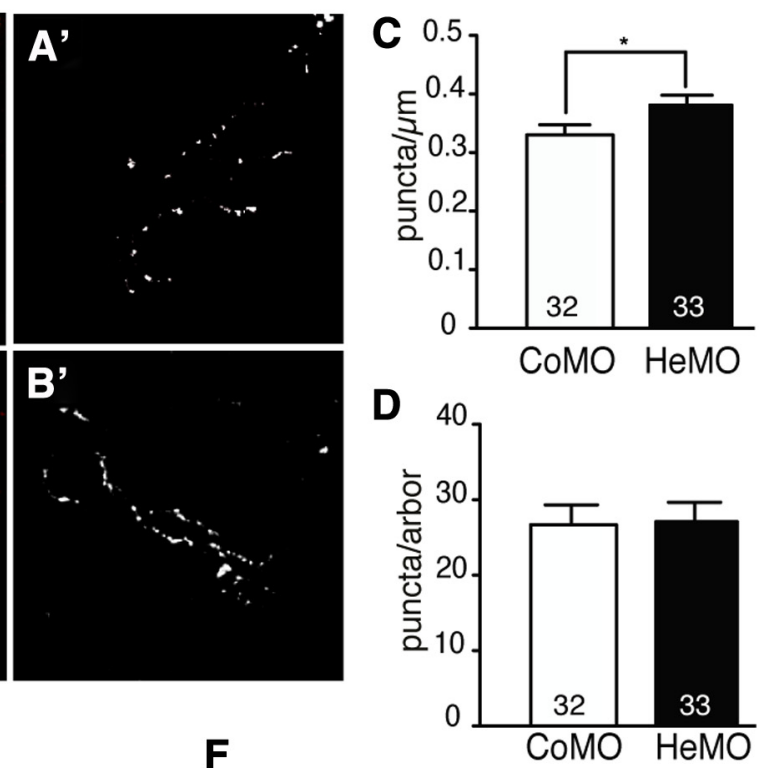

F

$\mathrm{HeMO}$

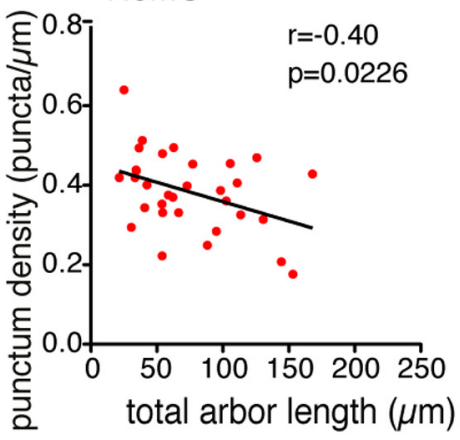

$r=-0.65$ $\mathrm{p}<0.0001$

Figure 7. Hermes depletion causes an increase in synaptic punctum density. $\boldsymbol{A}-\boldsymbol{B}^{\prime}$, Retinal axon terminals expressing GFP (green) and synaptophysin (red; syn-RFP) in the zebrafish tectum at $4 \mathrm{dpf}$. HeMO- or CoM0-injected embryos were coinjected with eGFP and syn-RFP, and the number of syn-RFP puncta was counted. C, $D$, HeM0-injected embryos showed a significant increase in epresent SEM. ${ }^{*} p<0.05$, Mann-Whitney test. $\boldsymbol{E}, \boldsymbol{F}$, Examining the correlation between punctum density and total arbor length revealed a significant inverse correlation in both control- $(\boldsymbol{E})$ and HeM0-injected embryos $[\boldsymbol{F} ; r=-0.65, p<0.0001$ (COMO) and $r=-0.40, p=0.0226$ (HeM0), Pearson's correlation]. The numbers of axons analyzed are indicated on bars. Scale bar, $10 \mu \mathrm{m}$.

Netrin-1, BDNF, and Slit-1, also have an effect on synaptogenesis (Campbell et al., 2007; Marshak et al., 2007; Marler et al., 2008; Manitt et al., 2009), suggesting that the two processes are linked. Therefore, we next investigated whether Hermes depletion also affects synapse formation. To visualize putative synapses, we used a syn-RFP construct that labels presynaptic terminals (Meyer and Smith, 2006), together with atoh7:GAPGFP to visualize single arbors (Fig. $7 A-B^{\prime}$ ). At $4 \mathrm{dpf}$, the syn-RFP signal was present as fluorescent puncta in CoMO-loaded axons at a density similar to that described previously (Fig. $7 A, A^{\prime}, C$ ) (Meyer and Smith, 2006). In contrast, at 4 dpf in HeMO-loaded axons, when the reduction in branch number is most apparent, the density of syn-RFP puncta per unit length of axon terminal was significantly higher than in controls (control, $0.33 \pm 0.02 / \mu \mathrm{m} ; \mathrm{HeMO}, 0.38 \pm 0.02 / \mu \mathrm{m} ; p<0.05$ Mann-Whitney test; Fig. 7C).

The inverse relationship between punctum density and arbor size seen above might suggest that the RGC has some kind of homeostatic control over the total number of synapses it is forming. We therefore counted that total number of syn-RFP puncta for each arbor. In line with the above hypothesis, we found that there was no significant difference between Hermes-depleted and control axons (control, $27.94 \pm$ 2.447; HeMO, $27.09 \pm 2.562$; not significant, 
A

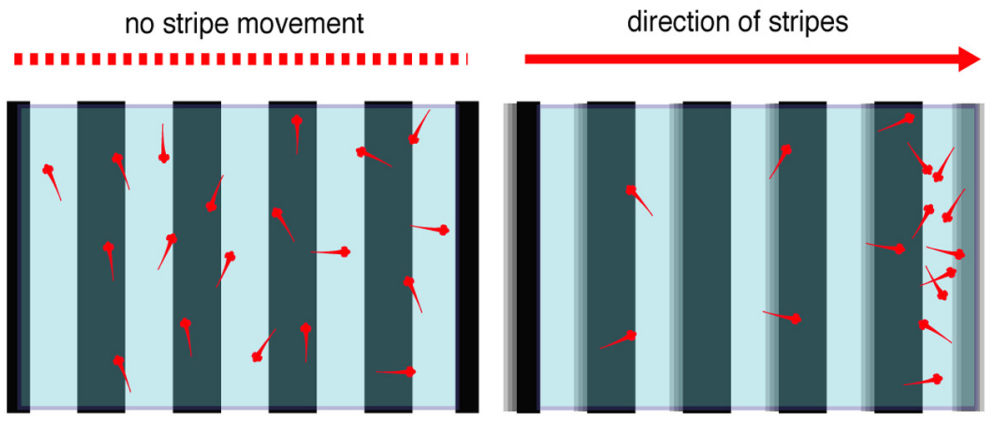

B
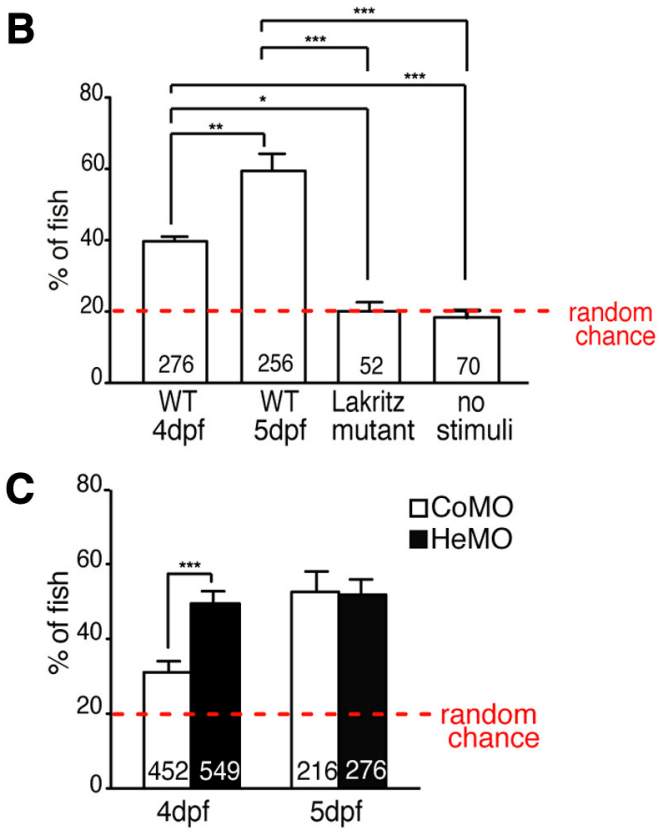

ratio: $\quad 0.2$
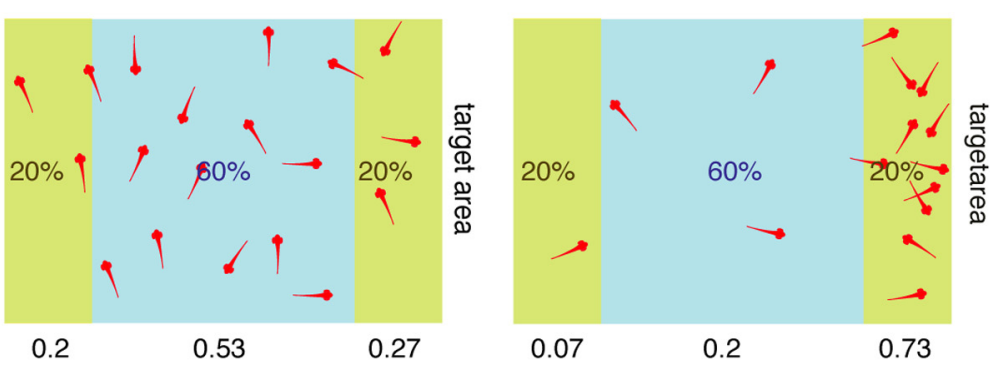

Figure 8. Hermes morphants exhibit stronger optomotor response. $\boldsymbol{A}$, Model of the OMR test chamber. An LCD screen underneath the transparent chamber provides the moving stimulus stripe pattern. Fish shown a nonmoving stripe pattern are randomly distributed in the chamber, whereas fish shown a directionally moving stripe pattern swim preferentially to the end zone in the direction of the motion. $\boldsymbol{B}$, WT embryos start responding at $4 \mathrm{dpf}$, and $>60 \%$ respond at $5 \mathrm{dpf}$, with Lakritz mutants and embryos showing a static pattern showing no response. Error bars represent SEM. ${ }^{*} p<0.05 ;{ }^{* *} p<0.01 ;{ }^{* * *} p<0.001$, ANOVA, Bonferroni posttest. C, HeM0-injected embryos perform significantly better than CoM0-injected embryos at 4 dpf, but this difference is absent at $5 \mathrm{dpf}$. ${ }^{* * *} p<0.001$, unpaired $t$ test. The numbers of embryos analyzed are indicated on the bars.

Mann-Whitney test; Fig. 7D). Thus, despite being smaller, Hermesdepleted axon arbors still contain the normal number of syn-RFP puncta.

If this inverse correlation is indicative of a homeostatic regulation of total synapse formation, it should be seen not only when comparing Hermes morphant arbors to controls, but also within control and morphant arbors of various sizes. We therefore examined the correlation between arbor size and syn-RFP density at $4 \mathrm{dpf}$ in both control and Hermes-depleted embryos. We found a strong continuous inverse correlation between arbor size and syn-RFP density at $4 \mathrm{dpf}(\mathrm{CoMO}, r=-0.65, p<0.0001$; Fig. $8 E$; HeMO, $r=-0.40, p<0.02$; Fig. $8 F)$.

Hermes knockdown leads to enhanced early visual behavior We next asked what effect the changes in synaptic density and arbor size might have on visual behavior by testing the response of control and Hermes morphant embryos in an OMR assay. Zebrafish embryos were placed in a rectangular transparent tank on a computer monitor and subjected to a $30 \mathrm{~s}$ duration stimulus of black/white stripe grating motions (Fig. 8A). Zebrafish larvae normally follow the direction of the moving stripes and accumulate at one end (target zone) of the tank. A positive response was scored for each fish within the target zone at the end of the stimuli, with the random chance value of occupying the target zone being 20\% (Fig. 8A). WT fish start responding to this assay at 4 $\mathrm{dpf}$, and by $5 \mathrm{dpf},>60 \%$ of WT embryos accumulate in the target area after a $30 \mathrm{~s}$ grating stimulus (Fig. 8B). There is no such accumulation when lakritz mutants lacking RGCs are used, or when a static rather than a moving grating is shown to WT fish (Fig. 8B). Surprisingly, when Hermes-depleted embryos were tested at $4 \mathrm{dpf}$, they showed a significantly stronger visual response compared to control-injected embryos (control, $31.06 \pm$ 2.99\%; HeMO, $49.46 \pm 3.31 \%$; $p<0.001$, Student's $t$ test; Fig.
$8 C)$. At $5 \mathrm{dpf}$, when the visual field was more fully formed, Hermes-depleted embryos responded at a similar level as control embryos (control, $52.57 \pm 5.47 \%$; HeMO, $51.84 \pm 4.08 \%$; $p>$ 0.05 , Student's $t$ test; Fig. $8 C$ ). These data suggest that the increased synaptic density seen in Hermes morphant zebrafish at 4 $\mathrm{dpf}$ is functional.

\section{Discussion}

The role of the RNA-binding protein Hermes was investigated during retinotectal development in Xenopus and zebrafish embryos. In both vertebrate species, we found Hermes-positive granules in the axons of maturing RGCs. Hermes (RPBMS and RBPMS2) shows a similar pattern of expression specific to the RGC layer of rats and mice (www.genepaint.org) (Piri et al., 2006; Kwong et al., 2010), indicative of a high degree of evolutionary conservation. Indeed, our functional studies show that knocking down Hermes produces a strikingly similar RGC axon arbor phenotype in two species that diverged $>350$ million years ago.

How Hermes is transported along axons to the growth cone is currently not known. As Hermes forms mRNP complexes with mRNAs (Gerber et al., 2002; Song et al., 2007), one possibility is that Hermes mRNP complexes are transported to growth cones via motor proteins traveling along microtubules in the RGC axon. The design of the dominant-negative Hermes RRM construct was optimized to retain RNA-binding activity of the RRM domain, while abrogating any protein functionality localized to the truncated C-terminal region. RRM overexpression experiments revealed that Hermes RRM is still trafficked to the growth cone but is no longer localized in granular structures, and the subsequent RGC arbor phenotype is similar to that of the Hermes MO-induced knockdown. Further studies are necessary to understand how Hermes binds to granules, how it is 
transported, and how it delivers its presently unknown mRNA cargo for translation.

How does Hermes regulate branch formation? Analyses of time-lapse movies of Hermes-depleted single axons showed a significant reduction of transient filopodia in $3 \mathrm{dpf}$ axons followed by a significant reduction of branch addition at $4 \mathrm{dpf}$, with no difference in branch retraction. This sequence of events is consistent with previous work on RGC arbor formation showing that it is often preceded by the formation of transient filopodia (Alsina et al., 2001; Meyer and Smith, 2006; Ruthazer et al., 2006; Campbell et al., 2007; Ben Fredj et al., 2010). Other RBPs, such as ZBP1, have been shown to regulate dendritic arborization by regulating translation of its target mRNA, $\beta$-actin (Perycz et al., 2011). Furthermore, axonal translation of cytoskeletal components promotes filopodia and branch formation in sensory axons (Spillane et al., 2012).

As branching and synapse formation could be linked, we investigated the effect of reducing Hermes levels on synapse formation. Our data indicate that loss of Hermes function leads to an increase in synaptic density per unit length of axon. However, since arbor size is reduced to the same extent as synaptic density is increased, the total number of synaptic puncta per arbor is unchanged in Hermes morphants. This suggests the possibility of homeostatic regulation of some kind, an idea that is supported by our finding that in both control injected and Hermes morphant fish, there is a significant inverse correlation between synaptic density and arbor size at $4 \mathrm{dpf}$. Homeostasis of synaptic input is an important mechanism to maintain a stable function of neuronal circuits in response to changes in activity and has been reported to play a role in the development of the visual system (Shah and Crair, 2008). For example, mice lacking spontaneous retinal waves during development have larger receptor fields than WT mice, but still maintain the same amount of total visual response (Chandrasekaran et al., 2007). Homeostasis is often regulated by a change in synaptic strength that can occur either on the presynaptic or postsynaptic site, but changes in synaptic number have also been reported (Kirov et al., 2004; Wierenga et al., 2006; Han and Stevens, 2009).

In light of these findings, how are we to interpret the Hermes morphant data? The existence of a homeostatic mechanism does not suggest a direction of causality. Thus, Hermes' main effect may be on branch formation, and the density of synapses changes in response. But it seems equally possible that the increased synaptic density in Hermes morphants results in fewer RGC axonal branches. Indeed, previous work has shown that filopodia formation is suppressed at mature synapses (Meyer and Smith, 2006), that visual activity can both decrease the number of extending branches while increasing branch retraction (Ruthazer et al., 2006), and that blocking activity can increase arbor growth (Ben Fredj et al., 2010). Our surprising finding that the early optomotor response of Hermes morphant zebrafish is actually enhanced compared to control embryos can be used to explain the arbor phenotype according to the homeostatic hypothesis. If Hermes is a negative regulator of synapse formation, the increased neuronal activity from too many synapses being formed too early could lead to the robust early visual behavior observed in the Hermes morphants, as well as the associated reduction in axonal arborization and transient filopodia. Further studies, however, are needed to identify whether synapse formation or axon branching is the primary target of Hermes activity.

In conclusion, we have provided evidence that the function of RNA-binding protein Hermes in RGC axons is associated with arbor and synapse formation. The inverse correlation between arbor size and density of puncta, which is apparent in both Hermes morphants and the control population, means that, independent of arbor size and complexity, there are approximately the same number of synapses per arbor. This suggests that RGCs have a homeostatic mechanism to regulate total synapse number, increasing the density of the forming synapse with decreasing arbor growth and vice versa. It will be of particular interest in the future to identify Hermes-bound mRNAs in RGC axons and to investigate the relevance of these RNAs for various aspects of axonal branching and synapse formation in the tectum.

\section{References}

Alsina B, Vu T, Cohen-Cory S (2001) Visualizing synapse formation in arborizing optic axons in vivo: dynamics and modulation by BDNF. Nature Neurosci 4:1093-1101. CrossRef Medline

Ben Fredj N, Hammond S, Otsuna H, Chien CB, Burrone J, Meyer MP (2010) Synaptic activity and activity-dependent competition regulates axon arbor maturation, growth arrest, and territory in the retinotectal projection. J Neurosci 30:10939-10951. CrossRef Medline

Campbell DS, Holt CE (2001) Chemotropic responses of retinal growth cones mediated by rapid local protein synthesis and degradation. Neuron 32:1013-1026. CrossRef Medline

Campbell DS, Stringham SA, Timm A, Xiao T, Law MY, Baier H, Nonet ML, Chien CB (2007) Slitla inhibits retinal ganglion cell arborization and synaptogenesis via Robo2-dependent and -independent pathways. Neuron 55:231-245. CrossRef Medline

Chandrasekaran AR, Shah RD, Crair MC (2007) Developmental homeostasis of mouse retinocollicular synapses. J Neurosci 27:1746-1755. CrossRef Medline

Concordet JP, Lewis KE, Moore JW, Goodrich LV, Johnson RL, Scott MP, Ingham PW (1996) Spatial regulation of a zebrafish patched homologue reflects the roles of sonic hedgehog and protein kinase $\mathrm{A}$ in neural tube and somite patterning. Development 122:2835-2846. Medline

Das T, Payer B, Cayouette M, Harris WA (2003) In vivo time-lapse imaging of cell divisions during neurogenesis in the developing zebrafish retina. Neuron 37:597-609. CrossRef Medline

Drinjakovic J, Jung H, Campbell DS, Strochlic L, Dwivedy A, Holt CE (2010) E3 ligase Nedd4 promotes axon branching by downregulating PTEN. Neuron 65:341-357. CrossRef Medline

Falk J, Drinjakovic J, Leung KM, Dwivedy A, Regan AG, Piper M, Holt CE (2007) Electroporation of cDNA/Morpholinos to targeted areas of embryonic CNS in Xenopus. BMC Dev Biol 7:107. CrossRef Medline

Gerber WV, Yatskievych TA, Antin PB, Correia KM, Conlon RA, Krieg PA (1999) The RNA-binding protein gene, hermes, is expressed at high levels in the developing heart. Mech Dev 80:77-86. CrossRef Medline

Gerber WV, Vokes SA, Zearfoss NR, Krieg PA (2002) A role for the RNAbinding protein, hermes, in the regulation of heart development. Dev Biol 247:116-126. CrossRef Medline

Grant P, Rubin E (1980) Ontogeny of the retina and optic nerve in Xenopus laevis. II. Ontogeny of the optic fiber pattern in the retina. J Comp Neurol 189:671-698. CrossRef Medline

Gumy LF, Yeo GS, Tung YC, Zivraj KH, Willis D, Coppola G, Lam BY, Twiss JL, Holt CE, Fawcett JW (2011) Transcriptome analysis of embryonic and adult sensory axons reveals changes in mRNA repertoire localization. RNA 17:85-98. CrossRef Medline

Han EB, Stevens CF (2009) Development regulates a switch between postand presynaptic strengthening in response to activity deprivation. Proc Natl Acad Sci U S A 106:10817-10822. CrossRef Medline

Hengst U, Jaffrey SR (2007) Function and translational regulation of mRNA in developing axons. Semin Cell Dev Biol 18:209-215. CrossRef Medline

Holt CE, Harris WA (1983) Order in the initial retinotectal map in Xenopus: a new technique for labelling growing nerve fibres. Nature 301:150-152. CrossRef Medline

Holt CE, Garlick N, Cornel E (1990) Lipofection of cDNAs in the embryonic vertebrate central nervous system. Neuron 4:203-214. CrossRef Medline

Hu M, Easter SS (1999) Retinal neurogenesis: the formation of the initial central patch of postmitotic cells. Dev Biol 207:309-321. CrossRef Medline

Jung H, Yoon BC, Holt CE (2012) Axonal mRNA localization and local 
protein synthesis in nervous system assembly, maintenance and repair. Nat Rev Neurosci 13:308-324. Medline

Kay JN, Finger-Baier KC, Roeser T, Staub W, Baier H (2001) Retinal ganglion cell genesis requires lakritz, a Zebrafish atonal homolog. Neuron 30:725-736. CrossRef Medline

Kiebler MA, Bassell GJ (2006) Neuronal RNA granules: movers and makers. Neuron 51:685-690. CrossRef Medline

Kirov SA, Goddard CA, Harris KM (2004) Age-dependence in the homeostatic upregulation of hippocampal dendritic spine number during blocked synaptic transmission. Neuropharmacology 47:640-648. CrossRef Medline

Kosaka K, Kawakami K, Sakamoto H, Inoue K (2007) Spatiotemporal localization of germ plasm RNAs during zebrafish oogenesis. Mech Dev 124: 279-289. CrossRef Medline

Kwong JM, Caprioli J, Piri N (2010) RNA binding protein with multiple splicing: a new marker for retinal ganglion cells. Invest Ophthalmol Vis Sci 51:1052-1058. CrossRef Medline

Leung KM, van Horck FP, Lin AC, Allison R, Standart N, Holt CE (2006) Asymmetrical beta-actin mRNA translation in growth cones mediates attractive turning to netrin-1. Nat Neurosci 9:1247-1256. CrossRef Medline

Lilienbaum A, Reszka AA, Horwitz AF, Holt CE (1995) Chimeric integrins expressed in retinal ganglion cells impair process outgrowth in vivo. Mol Cell Neurosci 6:139-152. CrossRef Medline

Lin AC, Holt CE (2007) Local translation and directional steering in axons. EMBO J 26:3729-3736. CrossRef Medline

Lunde BM, Moore C, Varani G (2007) RNA-binding proteins: modular design for efficient function. Nat Rev Mol Cell Biol 8:479-490. CrossRef Medline

Manitt C, Nikolakopoulou AM, Almario DR, Nguyen SA, Cohen-Cory S (2009) Netrin participates in the development of retinotectal synaptic connectivity by modulating axon arborization and synapse formation in the developing brain. J Neurosci 29:11065-11077. CrossRef Medline

Mann F, Ray S, Harris W, Holt C (2002) Topographic mapping in dorsoventral axis of the Xenopus retinotectal system depends on signaling through ephrin-B ligands. Neuron 35:461-473. CrossRef Medline

Marler KJ, Becker-Barroso E, Martinez A, Llovera M, Wentzel C, Poopalasundaram S, Hindges R, Soriano E, Comella J, Drescher U (2008) A TrkB/EphrinA interaction controls retinal axon branching and synaptogenesis. J Neurosci 28:12700-12712. CrossRef Medline

Marshak S, Nikolakopoulou AM, Dirks R, Martens GJ, Cohen-Cory S (2007) Cell-autonomous TrkB signaling in presynaptic retinal ganglion cells mediates axon arbor growth and synapse maturation during the establishment of retinotectal synaptic connectivity. J Neurosci 27:2444-2456. CrossRef Medline

McKee AE, Minet E, Stern C, Riahi S, Stiles CD, Silver PA (2005) A genomewide in situ hybridization map of RNA-binding proteins reveals anatomically restricted expression in the developing mouse brain. BMC Dev Biol 5:14. CrossRef Medline

Meyer MP, Smith SJ (2006) Evidence from in vivo imaging that synaptogenesis guides the growth and branching of axonal arbors by two distinct mechanisms. J Neurosci 26:3604-3614. CrossRef Medline

Mu X, Fu X, Sun H, Beremand PD, Thomas TL, Klein WH (2005) A gene network downstream of transcription factor Math5 regulates retinal progenitor cell competence and ganglion cell fate. Dev Biol 280:467-481. CrossRef Medline

Neuhauss SC, Biehlmaier O, Seeliger MW, Das T, Kohler K, Harris WA, Baier H (1999) Genetic disorders of vision revealed by a behavioral screen of 400 essential loci in zebrafish. J Neurosci 19:8603-8615. Medline

Neumann CJ, Nuesslein-Volhard C (2000) Patterning of the zebrafish ret- ina by a wave of sonic hedgehog activity. Science 289:2137-2139. CrossRef Medline

Nieuwkoop PD, Faber J (1967) Normal table of Xenopus laevis (Daudin). A systematical and chronological survey of the development from the fertilized egg till the end of metamorphosis, Ed 2. Amsterdam: North Holland.

Perycz M, Urbanska AS, Krawczyk PS, Parobczak K, Jaworski J (2011) Zipcode binding protein 1 regulates the development of dendritic arbors in hippocampal neurons. J Neurosci 31:5271-5285. CrossRef Medline

Piper M, Anderson R, Dwivedy A, Weinl C, van Horck F, Leung KM, Cogill E, Holt C (2006) Signaling mechanisms underlying Slit2-induced collapse of Xenopus retinal growth cones. Neuron 49:215-228. CrossRef Medline

Piri N, Kwong JM, Song M, Caprioli J (2006) Expression of hermes gene is restricted to the ganglion cells in the retina. Neurosci Lett 405:40-45. CrossRef Medline

Poggi L, Vitorino M, Masai I, Harris WA (2005) Influences on neural lineage and mode of division in the zebrafish retina in vivo. J Cell Biol 171:991-999. CrossRef Medline

Ruthazer ES, Li J, Cline HT (2006) Stabilization of axon branch dynamics by synaptic maturation. J Neurosci 26:3594-3603. CrossRef Medline

Sasaki Y, Welshhans K, Wen Z, Yao J, Xu M, Goshima Y, Zheng JQ, Bassell GJ (2010) Phosphorylation of zipcode binding protein 1 is required for brain-derived neurotrophic factor signaling of local beta-actin synthesis and growth cone turning. J Neurosci 30:9349-9358. Medline

Shah RD, Crair MC (2008) Mechanisms of response homeostasis during retinocollicular map formation. J Physiol 586:4363-4369. CrossRef Medline

Song HW, Cauffman K, Chan AP, Zhou Y, King ML, Etkin LD, Kloc M (2007) Hermes RNA-binding protein targets RNAs-encoding proteins involved in meiotic maturation, early cleavage, and germline development. Differentiation 75:519-528. CrossRef Medline

Spillane M, Ketschek A, Donnelly CJ, Pacheco A, Twiss JL, Gallo G (2012) Nerve growth factor-induced formation of axonal filopodia and collateral branches involves the intra-axonal synthesis of regulators of the actinnucleating Arp2/3 complex. J Neurosci 32:17671-17689. CrossRef Medline

Stuermer CA (1988) Retinotopic organization of the developing retinotectal projection in the zebrafish embryo. J Neurosci 8:4513-4530. Medline

Vignali R, Poggi L, Madeddu F, Barsacchi G (2000) HNF1(beta) is required for mesoderm induction in the Xenopus embryo. Development 127:1455-1465. Medline

Welshhans K, Bassell GJ (2011) Netrin-1-induced local beta-actin synthesis and growth cone guidance requires zipcode binding protein 1. J Neurosci 31:9800-9813. CrossRef Medline

Wierenga CJ, Walsh MF, Turrigiano GG (2006) Temporal regulation of the expression locus of homeostatic plasticity. J Neurophysiol 96:2127-2133. CrossRef Medline

Yao J, Sasaki Y, Wen Z, Bassell GJ, Zheng JQ (2006) An essential role for beta-actin mRNA localization and translation in $\mathrm{Ca} 2+$-dependent growth cone guidance. Nature Neurosci 9:1265-1273. CrossRef Medline

Zearfoss NR, Chan AP, Wu CF, Kloc M, Etkin LD (2004) Hermes is a localized factor regulating cleavage of vegetal blastomeres in Xenopus laevis. Dev Biol 267:60-71. CrossRef Medline

Zivraj KH, Tung YC, Piper M, Gumy L, Fawcett JW, Yeo GS, Holt CE (2010) Subcellular profiling reveals distinct and developmentally regulated repertoire of growth cone mRNAs. J Neurosci 30:15464-15478. CrossRef Medline

Zolessi FR, Poggi L, Wilkinson CJ, Chien CB, Harris WA (2006) Polarization and orientation of retinal ganglion cells in vivo. Neural Dev 1:2. CrossRef Medline 